Originalveröffentlichung in: Alemannien und der Norden. Internationales Symposium vom 18. - 20. Oktober 2001 in Zürich (Ergänzungsbände zum Reallexikon der germanischen Altertumskunde 43), Berlin/ New York 2004, S. $165-212$

Alemannien und der Norden - RGA-E Band 43 - Seiten 165-212

(c) Copyright 2003 Walter de Gruyter · Berlin · New York

\title{
Kontinentalgermanische Runeninschriften und „alamannische Runenprovinz“ aus archäologischer Sicht
}

\author{
MAX MARTIN
}

\section{Einleitung}

Vor gut zwanzig Jahren habe ich mich - an etwas entlegener Stelle - ein erstes Mal mit dem Problem der Runenritzungen auf frühmittelalterlichen Gegenständen beschäftigt. Dabei habe ich, als Archäologe, vor allem die auffällige, relativ späte Zeitstellung der als Träger dieser „südgermanischen“, nach heutigem Sprachgebrauch kontinentalgermanischen Inschriften dienenden Objekte hervorgehoben und nach einer mit dem archäologischen Befund vereinbaren Erklärung gesucht. ${ }^{1}$ Im folgenden sollen unter Berücksichtigung der nicht wenigen Neufunde die Überlegungen zu diesem Thema nochmals zusammengefaßt werden. $^{2}$

Bereits 1966 hatte J. Werner mit seiner Zusammenstellung der ältesten Bilddenkmäler der Germanen und der Kartierung der ältesten Runeninschriften des 3. und 4. Jahrhunderts das damalige Kerngebiet der germanischen Welt, die germanische „Koine“ der römischen Kaiserzeit, prägnant umrissen. ${ }^{3}$ Im Laufe der späten Kaiserzeit und der nachfolgenden Völkerwanderungszeit setzte eine bisher noch nicht umfassend diskutierte Entwicklung ein, die man als ein Auseinanderdriften (oder Auseinanderstreben) dieser germanischen Welt bezeichnen könnte. Im Gefolge dieses Prozesses dürfen wir - jedenfalls aus archäologischer Sicht - von drei germanischen Hauptgruppen, den Nord-, Westund Ostgermanen, sprechen.

Zu den Nordgermanen zählen nebst den skandinavischen Völkern die Sachsen Norddeutschlands und die angelsächsische Bevölkerung Britanniens. Die Westgermanen, bestehend aus den Rhein-Weser-Germanen und den Elbgerma-

Martin 1977; vgl. auch meinen kurzen Beitrag mit dem provokativen Titel ,Schrift aus dem Norden“ in einem Ausstellungskatalog (Martin 1997), dem im folgenden einige Formulierungen entnommen sind.

2 Für freundlich gewährte Auskunft und Hilfestellung zu Neu- und Altfunden danke ich U. von Freeden, Frankfurt a. M.; P. Kamber, Basel; D. Reimann und B. Wührer, München; T. Brendle, München, M. Knaut, Berlin; D. Quast, Mainz.

3

Werner 1966: Abb. 15. 
nen, aus denen die Franken, Alamannen, Thüringer und Langobarden hervorgingen, orientierten sich schon früh nach Westen und Südwesten und hin zum römischen Reich - die Langobarden allerdings auf einem Umweg. Ostgermanische Völker, vorab Goten, Gepiden, Heruler, Skiren usw., gelangten hingegen von Nordosten und Osten her, über Südrußland und die Karpaten, ins Imperium Romanum. Die germanische Welt lebte sich in diesem Prozeß gewissermaßen auseinander!

$\mathrm{Da} \beta$ diese hier nur grob skizzierte Entwicklung zu fundamentalen, auch archäologischen Unterschieden zwischen West- und Ostgermanen führte, verrät unter anderem die seit etwa $400 \mathrm{n}$. Chr. unterschiedliche Frauentracht der West- und Ostgermanen: Bei den Ostgermanen lebte während des gesamten Frühmittelalters als weibliches Hauptkleid der seit prähistorischen Zeiten übliche Peplos weiter, der aus einem Stoffzylinder bestand, also ärmellos war und an den Schultern durch ein Fibelpaar, die sogenannten Peplosfibeln, zusammengehalten wurde.

Bei den Franken, Alamannen, Thüringern und Langobarden im Westen (auch die Bajuwaren wären hinzuzuzählen) rezipierten die Frauen hingegen bereits um 400 das antike Hauptkleid, die Tunika, die Ärmel besaß und keine Fibeln benötigte. Trotzdem gehörten zur westgermanischen Frauentracht auch während der Merowingerzeit Fibeln: Die vornehme Westgermanin trug in der Regel gleich zwei Fibelpaare unterschiedlicher Größe: ${ }^{4}$ Ein Paar kleinerer Fibeln - der Archäologe nennt sie sinnigerweise Kleinfibeln - verschloß am Hals einen Umhang oder Mantel; das größere Fibelpaar, die sogenannten Bügelfibeln, schmückte vermutlich - als repräsentatives Standeszeichen - eine Schärpe und kennzeichnete die soziale Stellung der Trägerin; nicht zufällig und vermutlich nicht nur ihrer Größe wegen wurden mit Vorliebe Bügelfibeln als Runenträger gewählt.

Die Verbreitung der ältesten Runendenkmäler, sowohl der „,archaischen Runenzeit bis etwa 400 “5 wie auch all jener, die mit Sicherheit noch der Zeit vor 500 angehören, bietet ein merkwürdiges Bild. ${ }^{6} \mathrm{Da}$ sich im Norden, im skandinavischen Raum, früheste Zeugnisse finden, kann nicht erstaunen, wohl aber die Beobachtung, daß sich außerhalb Skandinaviens bis um 500 sogenannte kontinentalgermanische Runenritzungen nur gerade an der Nordseeküste und in deren Hinterland sowie - in weiter Streuung - in Ost- und Südosteuropa finden lassen, nicht aber in den nach Süden anschließenden Kernregionen des freien Germanien. So etwa bildet sich die mit vielen Belegen dicht besetzte "alamannische Runenprovinz" mitsamt einigen Belegen in benachbarten Land-

4 Vgl. etwa in Abb. 3 den Fibelbestand des alamannischen Friedhofs von Hemmingen, Kr. Ludwigsburg, in dem - wegen seiner frühen Zeitstellung - erst bei wenigen Bestattungen nebst dem obligaten Bügelfibelpaar auch Kleinfibeln angetroffen wurden.

5 Seebold 1994: 64.

6 Vgl. meine Kartierung in: Martin 1997: 499, Abb. 579. 
schaften erst im mittleren 6. Jahrhundert, also vergleichsweise spät heraus. Mit den ältesten kontinentalen Runendenkmälern, auf die im folgenden zunächst eingegangen wird, stehen jene jüngeren „alamannischen“ Ritzungen weder geographisch noch zeitlich in Zusammenhang, wie noch zu zeigen sein wird.

\section{Die ältesten kontinentalgermanischen Runendenkmäler bis um 500}

\subsection{Nordgermanisches Gebiet}

Aus dem norddeutschen Küstengebiet und dem zugehörigen Hinterland zwischen Elbe und Rhein sind für die Zeit vor 500 Runenritzungen auf dem dendrochronologisch „bald nach 421" datierten Holzschemel von der Fallward (Lkr. Cuxhaven) $)^{7}$ und auf einer Silberscheibe im Spathagrab von Liebenau (Kr. Nienburg/Weser) ${ }^{8}$ zu nennen, die beide der ersten Hälfte des 5. Jahrhunderts angehören. Vieles spricht dafür, daß in den betreffenden beiden Männergräbern Sachsen, d.h. Nordgermanen bestattet waren. ${ }^{9}$ Auch weitere, vielleicht ebenfalls noch vor 500 datierbare Objekte mit Runenritzung wie z.B. der Kamm aus Kanntens, ${ }^{10}$ aber auch jüngere beschränken sich auf friesische Terpen und sächsische(?) Siedlungen an der Nordseeküste. Hier, in diesem von Nordgermanen besiedelten Küstensaum und dessen Hinterland lebt die vergleichsweise früh bezeugte Runenschrift offensichtlich nach 500 genauso weiter wie in den angrenzenden Gebieten Skandinaviens und Britanniens. ${ }^{11}$

\subsection{Ostgermanische Gebiete}

Ein anderer Zweig früher runenbeschrifteter Objekte ist auf dem Kontinent eindeutig mit ostgermanischen Bevölkerungsgruppen zu verbinden: Den Anfang machen dabei die in die späte Kaiserzeit und anschließende Völkerwanderungszeit zu datierenden Lanzenspitzen mit Runenritzung, die von der Oder bis an den Oberlauf des Pripjet bezeugt sind. ${ }^{12} \mathrm{Da} ß$ wir diese Schriftzeugnisse mit Ostgermanen verbinden dürfen, verrät weniger deren lockere Streuung im Be-

7 Schön 1999: 82 f. mit Abb.; Düwel 2001: 66.

8 Cosack 1982: Taf. 8, 32; Düwel 2001: $62 \mathrm{f}$.

9 Vgl. etwa Böhme 1999.

10 Quak 1994: 221.

$11 \mathrm{Zu}$ Runeninschriften aus England und Friesland vgl. jetzt zusammenfassend Düwel 2001: 71-87.

12 Seebold 1994: Nrn. C 15-18. 
reich ostgermanisch geprägter „Kulturgruppen“ ${ }^{13}$ sondern eine derzeit erst bescheidene Reihe noch weiter nach (Süd)Osten streuender jüngerer Belege, die unzweifelhaft mit ostgermanischem Trachtschmuck vergesellschaftet sind und mit ihrer Verbreitung gleichsam die zunächst süd-, dann westwärts gerichtete „Wanderung“ ostgermanischer, vorab gotischer Volksgruppen zum Schwarzen Meer und ins Karpatenbecken nachzeichnen.

In einem Frauengrab mit ostgermanischer Blechfibel des späteren 4. Jahrhunderts aus Leţcani (rumänische Moldau) fand sich der bekannte, mit Runenschrift versehene Spinnwirtel. ${ }^{14}$ Aus dem im mittleren 5. Jahrhundert verborgenen Schatzfund von Pietroassa (Walachei), aus dem unter anderem ostgermanische Fibeln vorliegen, stammt der noch besser bekannte „Runenring“ mit der Inschrift dem König (?) der Goten heilig. ${ }^{15}$

Weitere Belege kommen aus Pannonien: Aus dem Sonderfriedhof einer ostgermanischen Bevölkerungsgruppe der Oberschicht bei Szabadbattyán (Kom. Fejér) östlich des Plattensees, in dem aus mindestens fünf gut bis reich ausgestatteten Frauengräbern gleich fünf ostgermanische Silberblechfibeln etwa des zweiten Viertels des 5. Jahrhunderts gefunden wurden, kennen wir eine zeitgleiche silberne Gürtelschnalle mit Runenzeichen auf der Rückseite des Beschlags. ${ }^{16}$ Die Schnalle ist zwar zweifellos ein qualitätvolles Erzeugnis der „spätrömischen Kunstindustrie“, doch dürfte sie einst, wie etwa das zeitgleiche Frauengrab von Smolín (Mähren) ${ }^{17}$ mit seinem ostgermanischen Bügelfibelpaar und einer verwandten Schnalle belegt, mit hoher Wahrscheinlichkeit von einer der fünf Frauen als Peplosverschluß und damit als zweitwichtigster (metallener) Bestandteil der damaligen ostgermanischen Frauentracht getragen worden sein.

Vermutlich nicht zufällig sind auf einer weiteren ostgermanischen Silberblechfibel, die zusammen mit ihrem paarigen Gegenstuick unter der Fundortangabe Ménföcsanak (Kom. Sopron) im Xantus Janos-Museum in Györ aufbewahrt wird, ${ }^{18}$ buchstabenartige Zeichen vorhanden, bei denen es sich möglicherweise um Runen handelt. ${ }^{19}$

Zweifelsfreie Runenzeichen trägt schließlich eine der beiden gegossenen, kerbschnittverzierten Bügelfibeln, die mit einigen vergoldeten Silberblechperlen und einem Paar Trinkschalen aus Silber zu einem im römischen Amphi-

13 Vgl. etwa die Übersicht bei Bierbrauer 1994.

14 Seebold 1994: Nr. E 4.

15 Seebold 1994: Nr. E 3; Nedoma 2000: 24 und Abb. 12; Düwel 2001: $31 \mathrm{f}$.

16 K.-J. Nr. 167; Kiss 1980: Taf. 9.

17 Tejral 1973: Abb. 4,2.3; 5,6; Germanen, Hunnen und Awaren 1987: Taf. 55.

18 Publiziert (ohne Hinweis auf Schriftzeichen) in: Severin 1982: 479 und Taf. 25 links. Für freundliche Hilfe, Fotoaufnahmen und weitere Angaben danke ich P. Tomka, Györ.

19 Eine Beurteilung der Zeichen hat freundlicherweise R. Nedoma, Wien, übernommen. 

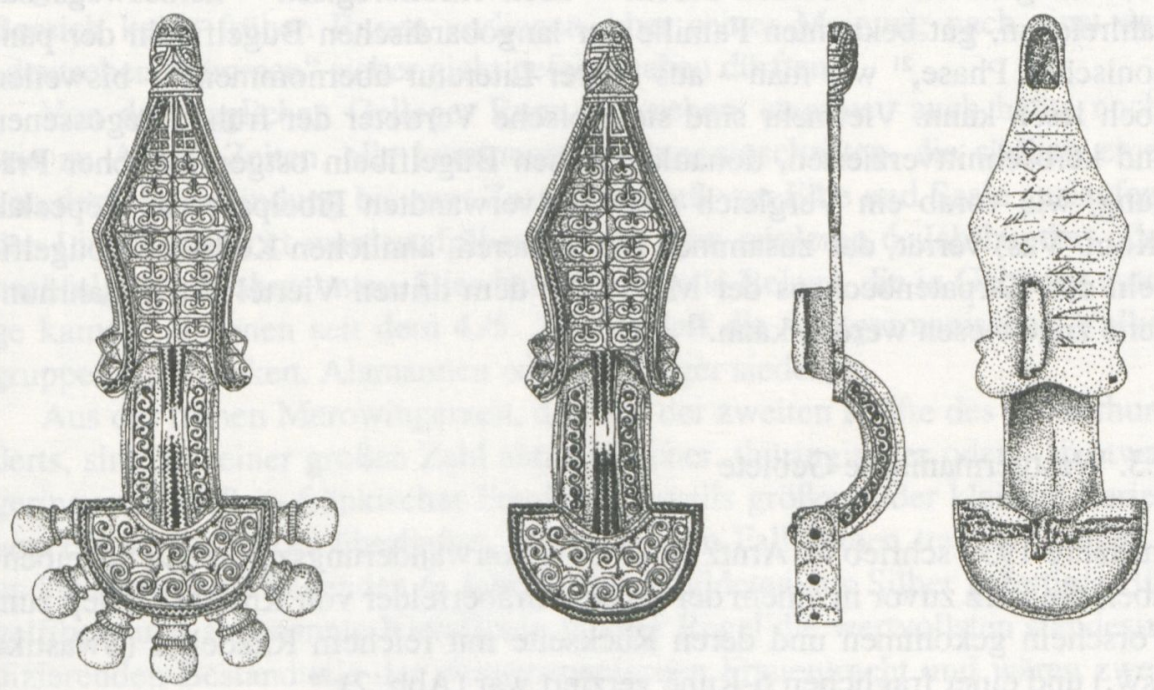

Abb. 1: Aquincum, Amphitheater. Bügelfibelpaar aus einem Schatzfund. (Maßstab 1:2). Vgl. Anm. 20.

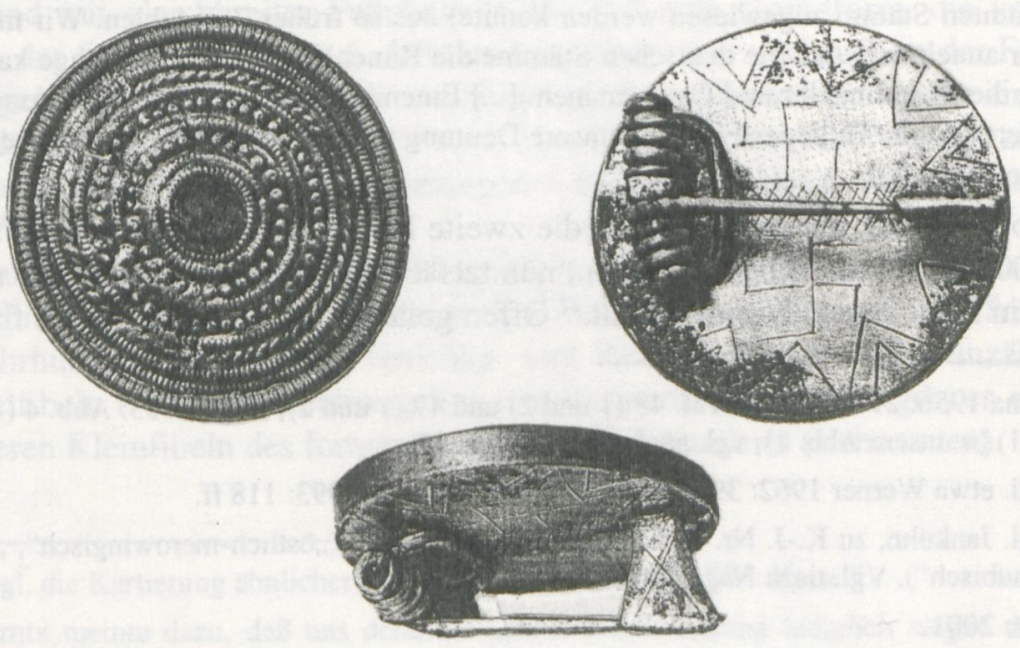

Abb. 2: Krefeld-Gellep. Scheibenfibel aus einem zerstörten Grab der späten Kaiserzeit. (Maßstab 1: 1). Vgl. Anm. 24. 
theater von Aquincum bei Budapest entdeckten Schatzfund gehören (Abb. 1). ${ }^{20}$ Mit ihrem sauberen Spiralkerbschnitt und ihrer beachtlichen Größe von $13,2 \mathrm{~cm}$ gehören die beiden Fibeln - auch chronologisch - keineswegs zur zahlreichen, gut bekannten Familie der langobardischen Bügelfibeln der pannonischen Phase, ${ }^{21}$ wie man - aus älterer Literatur übernommen ${ }^{22}$ - bisweilen noch lesen kann. Vielmehr sind sie typische Vertreter der frühen gegossenen und kerbschnittverzierten, donauländischen Bügelfibeln ostgermanischer Prägung, wie vorab ein Vergleich mit dem verwandten Fibelpaar aus Répcelak (Kom. Vas) verrät, das zusammen mit weiteren, ähnlichen Kerbschnittbügelfibeln des Karpatenbeckens der Mitte oder dem dritten Viertel des 5. Jahrhunderts zugewiesen werden kann. $^{23}$

\subsection{Westgermanische Gebiete}

Im Jahre 1937 schrieb H. Arntz zu einer völkerwanderungszeitlichen Scheibenfibel, die kurz zuvor in einem der großen Gräberfelder von Krefeld-Gellep zum Vorschein gekommen und deren Rückseite mit reichem Ritzdekor (Swastika usw.) und einer fraglichen o-Rune verziert war (Abb. 2): ${ }^{24}$

Das Zeichen auf dem Nadelhalter der Gelleper Scheibenfibel ist nach meiner Ansicht eine germanische o-Rune. [...] Der Gelleper Fund ist von großer Wichtigkeit, da uns auf dem Festland, soweit es sich nicht um Ostgermanen [...] handelt, Runeninschriften (bis auf die Schnalle von Szabadbattyán in Ungarn, die noch keinem bestimmten Stamm zugewiesen werden konnte) aus so früher Zeit fehlen. Wir müssen aber annehmen, daß die deutschen Stämme die Runeninschrift ebenso lange kannten wie die Skandinavier und Ostgermanen. [...] Einen ersten Beweis für diese Annahme liefert nun die Gelleper Fibel; ist unsere Deutung richtig, so trägt sie die älteste deutsche Rune. ${ }^{25}$

$\mathrm{Ob}$ die Fibel, die man heute in die zweite Hälfte des 4. Jahrhunderts ${ }^{26}$ oder um 400 und später(?) datieren kann, nun tatsächlich eine Rune trägt oder nicht, sei dem Runologen anheimgestellt. ${ }^{27}$ Offen gelassen sei auch, ob sie als fränki-

20 Bóna 1956: 217-220 und Taf. 48 (1 und 2) und 49 (1 und 2); Nagy 1993: Abb. 4 (1) und 5 (1) (= unsere Abb. 1); vgl. auch Düwel 2001: 57.

21 Vgl. etwa Werner 1962: 39 und 63-73 und Bierbrauer 1993: $118 \mathrm{ff}$.

22 Vgl. Jankuhn, zu K.-J. Nr. 7; Werner 1962: 67 und 72 („östlich-merowingisch“, „norddanubisch"). Vgl. dazu Nagy 1993.

23 Kiss 2001.

24 Abb. 2 nach Steeger 1937: Taf. 19 und 20. Bei Pirling 1979: Abb. 4 ist die Fibel mit falsch montierter Verschlußkonstruktion wiedergegeben (frdl. Hinweis meiner Frau).

25 H. Arntz, in: Steeger 1937: Kommentar zu Taf. 19 und 20.

26 Böhme 1985: 79 („type d'Altenwalde, seconde moitié du IVe siècle“).

27 Vgl. Düwel 2001: 67. 
scher oder sächsischer Trachtschmuck zu bezeichnen ist. ${ }^{28}$ Wichtiger ist, daß schon Arntz damals klar erkannte, daß bis auf die oben bereits angesprochenen ostgermanische Belege ,auf dem Festland“, d. h. aus dem westgermanischen Bereich keine frühen Runen vorliegen, aber seiner Meinung nach einst den „deutschen Stämmen“ sicher nicht gefehlt haben dürften. ${ }^{29}$

Von der fraglichen Gelleper Rune abgesehen, stammen auch heute noch, wie zu Arntz' Zeiten, alle kontinentalen Runeninschriften, die südlich einer von der Rheinmündung bis zum Zusammenfluß von Elbe und Saale verlaufenden Linie ${ }^{30}$ entdeckt wurden, frühestens aus dem mittleren 6. Jahrhundert oder nachfolgenden Jahrzehnten. Dies betrifft also alle Belege, die in Gebieten zutage kamen, in denen seit dem 4./5. Jahrhundert die westgermanischen Volksgruppen der Franken, Alamannen oder Thüringer siedelten.

Aus der frühen Merowingerzeit, d.h. aus der zweiten Hälfte des 5. Jahrhunderts, sind aus einer großen Zahl alamannischer, thüringischer oder - in etwas geringerem $\mathrm{Maße}$ - fränkischer Friedhöfe jeweils größere oder kleinere Serien von Fibeln aus Silber überliefert, die in keinem Fall Runen tragen. Damals und auch im nachfolgenden 6. Jahrhundert - bildeten aus Silber gefertigte Bügelfibeln und sogenannte Kleinfibeln in aller Regel die wertvollsten standesindizierenden Bestandteile der westgermanischen Frauentracht und wären zweifellos, wie später, als Träger von Runenritzungen ausgewählt worden. Unter dem Fibelbestand des alamannischen Friedhofs von Hemmingen dominieren bei den Bügelfibeln, wie anderswo in der Alamannia, die für die alamannische Tracht typischen Exemplare mit halbrunder Kopfplatte mit drei bis fünf Knöpfen und mit gleichbreiter Fußplatte (Abb. 3), ${ }^{31}$ eine Grundform, die von der Mitte des 5. bis ins frühere 6. Jahrhundert beliebt war und auch in der Francia getragen wurde. ${ }^{32}$ Unter Hunderten derartiger Bügelfibeln bzw. -paare sind nur gerade vier späte Vertreter mit Runen versehen worden (Abb. 4), die zeitlich die lange Reihe der mit Runen versehenen Bügelfibeln des 6. Jahrhunderts anführen (siehe unten).

Auch bei den sogenannten Kleinfibeln, die paarweise einen Umhang zu verschließen pflegten, blieben die frühen Formen des späteren 5. und früheren 6. Jahrhunderts, vor allem Pferdchen- und Reiterfibeln sowie die unzähligen Vogelfibeln (Abb. 3), durchweg frei von Runenritzung; solche gibt es erst an jüngeren Kleinfibeln des fortgeschrittenen 6. Jahrhunderts (siehe unten).

\footnotetext{
28 Vgl. die Kartierung ähnlicher Schalenfibeln bei Böhme 1974: Karte 7.

29 Arntz meinte dazu, daß uns derartige „frühe Funde bislang lediglich wegen des verwandten Materials (Holz, Knochen) vorenthalten" seien (Arntz, in: Steeger 1937).

30 Mit dieser schematischen „Grenzziehung“ sollen die norddeutschen, d.h. nordgermanischen Vorkommen ausgeschlossen werden.

31 Abb. 3 zusammengestellt nach Müller 1976.

32 Vgl. A. Koch 1998: Karten 3-13.
} 


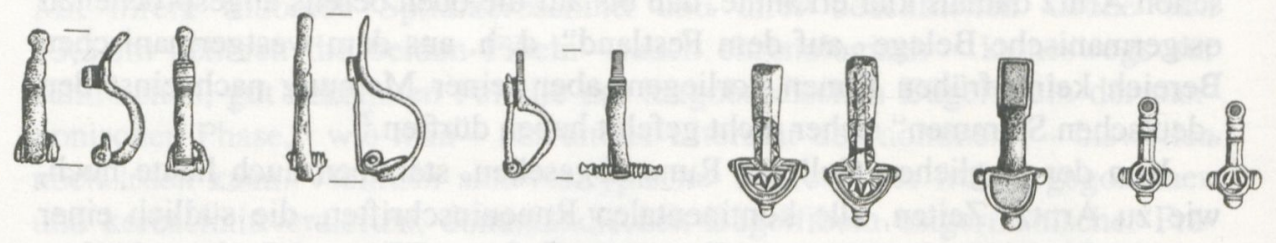
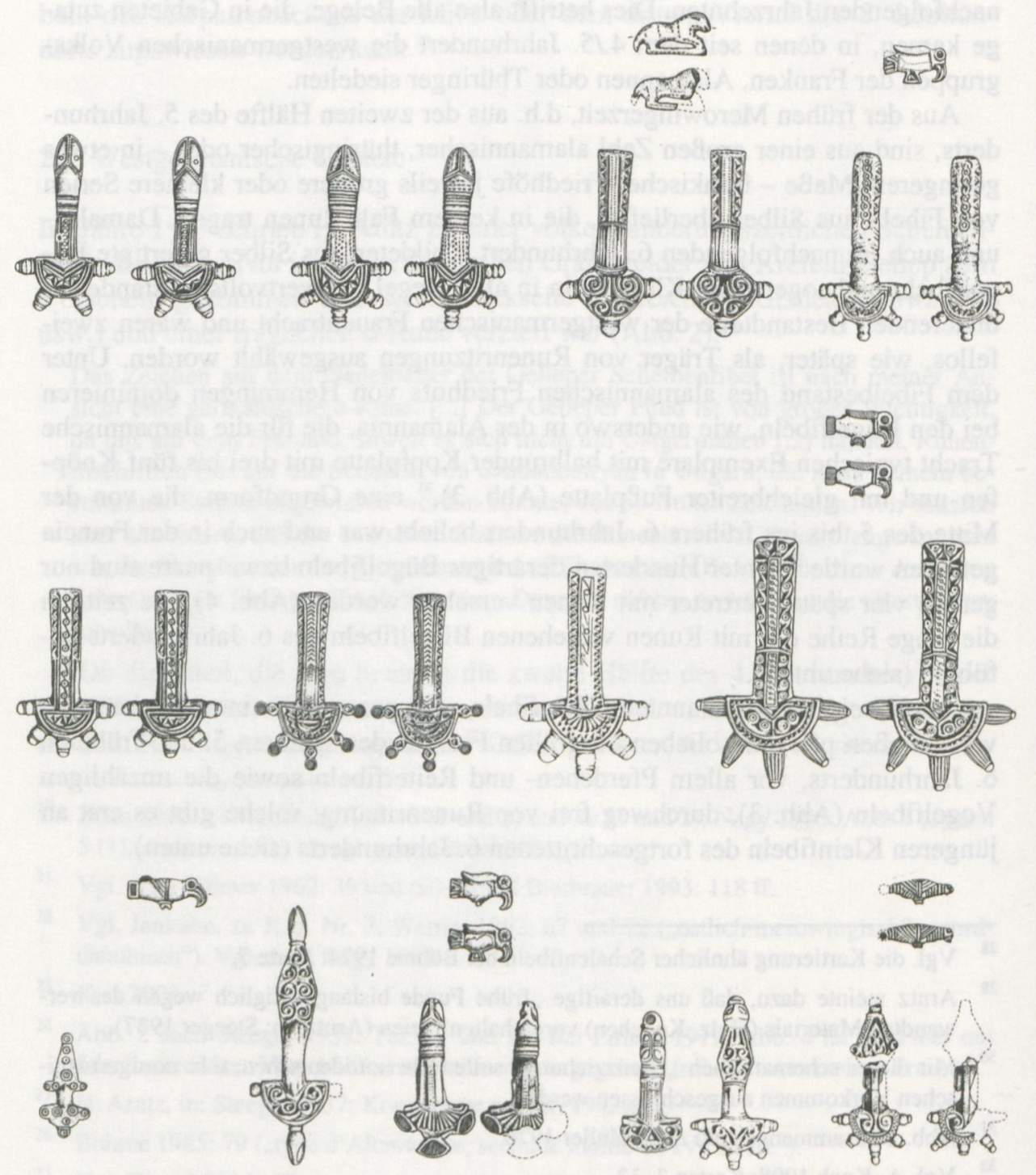
Abb. 3: Hemmingen (Kr. Ludwigsburg), alamannisches Gräberfeld. Gesamtbild der Armbrust-, Bügel- und Kleinfibeln. Maßstab $1: 3$. Vgl. Anm. 31.

Eine endgültige Bestätigung dafür, daß im westgermanischen Bereich während des 5 . und früheren 6 . Jahrhunderts keine Runenritzung vorkommt, liefern alle anderen Gruppen runentragender Gegenstände (Behälter, Waffen, Gürtelteile usw.), da auch diese nie aus Grabfunden stammen, die vor das mittlere 6. Jahrhundert zu datieren wären (siehe unten).

Eine erste Ausnahme von dieser Regel könnte ein aus dem Kunsthandel angekaufter Halsring aus Silber bilden, der bei Aalen zum Vorschein gekommen sein soll. Dessen Reifmitte ist an der Unterseite mit einer kurzen Runenritzung versehen. ${ }^{33}$ Die Ringform ist für alamannisches Gebiet fremdartig; der Granatschmuck der Reifmitte soll laut B. Arrhenius erst im 6. Jahrhundert angebracht worden sein, was auch für die Runen gelten könnte. ${ }^{34}$ Vor kurzem fand sich nun aber bei regulären Grabungen in einem Frauengrab bei Herrenberg (Kr. Böblingen), das noch dem 5. Jahrhundert angehört, ein sehr ähnlicher, granatgeschmückter Halsring aus vergoldetem Silber. ${ }^{35}$ Dennoch bleibt weiterhin offen, ob die beiden Halsringe in der Alamannia genuin sind und ob die Runen des Aalener Rings, selbst wenn jetzt nichts mehr gegen eine Datierung von Ring und Runen ins 5. Jahrhundert spricht, erst in Süddeutschland eingeritzt wurden. Gerne möchte man mehr kennen als nur einen einzelnen Beleg.

\section{4, Ergebnis}

Bis in die Zeit um 500 ist kontinentale, d.h. außerhalb Skandinaviens geübte Runenritzung nur gerade in zwei, recht ungleich großen Regionen bezeugt: Zum einen an der Küste Nordwestdeutschlands und in deren Hinterland sowie in angrenzenden Küstenstrichen der Niederlande, zum andern - in auffallend lockerer Streuung - von der Oder bis in den Südosten Polens sowie von der Moldau über die Walachei bis ins Karpatenbecken.

Archäologisch ist die erste Gruppe von Runenritzungen mit nordgermanischen Bevölkerungsgruppen, vorab Sachsen und Friesen, zu verbinden. In dieser Gruppe sind Runen auch über die Zeit von 500 hinaus bezeugt, was wegen des engen Kontakts zum angrenzenden Skandinavien und zum angelsächsischen Britannien nicht verwundert. Diese epigraphische „Koine“ der Nordger-

33 Kat. Göttingen: Nr. 1; Wamers 2000: Abb. 4 und 11; Nedoma 2000.

B. Arrhenius, in: Wamers 2000: $14 \mathrm{f}$.

35 Oeftiger/Dollhopf 2001: Abb. 126-128; das vom linken Arm der Toten teilweise überlagerte „ca. $30 \mathrm{~cm}$ lange Schmuckgehänge“ aus Perlen, Amuletten usw. findet seine besten Parallelen in gut bis reich ausgestatteten Frauengräbern des 5. Jahrhunderts (Ament 1992: Abb. 6 und 7). 
manen kann nicht erstaunen und muß im folgenden auch nicht weiter angesprochen werden.

Bei der zweiten Gruppe von Runeninschriften, die ostgermanischen Volksgruppen zuzuweisen sind, reichen die Belege nur gerade ins mittlere 5. Jahrhundert; der späteste ist die Runenritzung auf der Aquincumer Fibel (Abb. 1). Bisher sind weder unter den mit Ostgoten zu verbindenden Funden Italiens noch im reichen Fundstoff des westgotischen Spanien Runenritzungen bekannt geworden. Ihre Verwendung endet demnach im ostgermanischen Milieu kurze Zeit nach dem Übertritt ihrer Träger auf den Boden des (ehemaligen) Imperium Romanum.

Eine weitere Gruppe früher Runenritzungen, die man den Westgermanen zuschreiben müßte, existiert nicht, weder im fränkischen Bereich, wo man bestenfalls den unsicheren Beleg der Gelleper Fibel (Abb. 2) anführen könnte, noch in thüringischen Landschaften oder der Alamannia, für die allenfalls der (isolierte!) Beleg des erwähnten Aalener Halsringes zu nennen wäre.

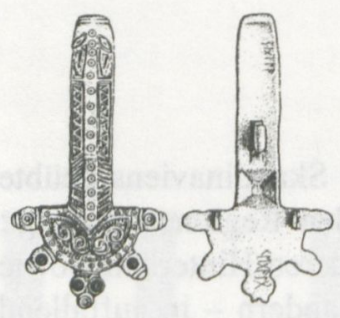

A 1

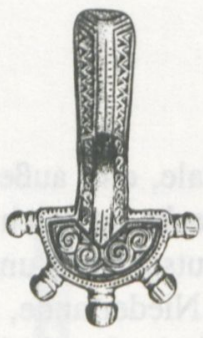

A 2

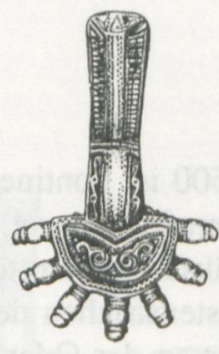

A 3

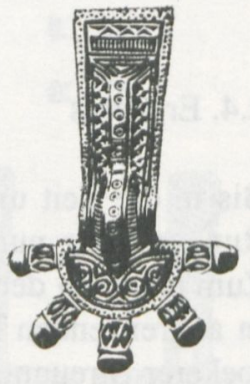

A 4

Abb. 4: Die mit Runen versehenen Bügelfibeln von München-Aubing Grab 303 (A 1), Basel-Kleinhüningen Grab 115 (A 2) und Hohenstadt (Kr. Göppingen) (A 4). Maßstab $1: 3$. Vgl. Liste A. 
3. Die „alamannische Runenprovinz“ und angrenzende Regionen (ca. 530-620)

\subsection{Einleitung}

Ein ganz anderes Bild runischer Schriftkultur bietet die Alamannia während der zweiten Hälfte des 6. Jahrhunderts: Nunmehr sind in Süddeutschland, aber auch in angrenzenden Regionen - von Mitteldeutschland und dem Mittelrheingebiet im Norden bis zum Alpenrand im Süden sowie mit einzelnen Belegen bis nach Ostfrankreich hinein - eine stattliche Zahl von Gegenständen, insbesondere Fibeln, mit Runen versehen. Im folgenden konzentriere ich mich auf eine rein archäologische Bewertung dieser Objekte: Wo sind wann welche mit Runen beschriftete Gegenstände dem Boden anvertraut worden? Welche Aussagen zu den Besitzern dieser Gegenstände sind aus archäologischer Sicht möglich?

Die Fundliste der Runen tragenden Fibeln (Listen A-K, S. 199 ff.; Abb. 4 8) enthält nicht nur die „,alamannischen“ Belege, sondern auch die der benachbarten Landschaften, in denen westgermanische Bevölkerungsgruppen lebten: In Westfalen (E 7), am Harz (D 2), in Mitteldeutschland (B 2), am Mittelrhein (B 6, C 4), in Rheinhessen (B 1, H 1), Hessen (C 2, E 2), im Münchner Raum (A 1, D 3, K 2, K 3) sowie in den Ardennen (K 1). Ein einzelner Beleg stammt aus dem Burgund (D 1). Nebst den Fibeln - auf ihnen finden sich fast zwei Drittel aller Runenritzungen - werden wegen ihrer ebenfalls fast durchweg präzis bestimmbaren Zeitstellung die mit Runen versehenen Waffen(teile) und Gürtel(teile) besprochen (Listen Wa und Gü, S. 205 f.). Diese beiden Gruppen bleiben, bis auf eine Rahmenschnalle aus Weimar (Gü 3), ganz auf die Alamannia konzentriert.

Einige wenige andere Runenritzungen - auf kleinen Behältern, ${ }^{36}$ Bernsteinperlen, ${ }^{37}$ einem Sieblöffel, ${ }^{38}$ einem Holzstab ${ }^{39}$ usw. - werden hier nicht behandelt, widersprechen aber mit ihrer (meist weniger scharfen) Datierung und Verbreitung nicht den im folgenden ermittelten Ergebnissen.

Soweit zu unserem Untersuchungsmaterial Fundumstände bekannt sind, stammen alle Belege mit Sicherheit oder doch sehr hoher Wahrscheinlichkeit

36 Amulettkapsel aus Grab 17 von Arlon (Belgien) (Opitz Nr. 2); Bronzekapsel von Schretzheim Grab 22 (Opitz Nr. 38); Elfenbeinbüchschen aus dem Mädchengrab von Gammertingen (Opitz Nr. 18).

Perle aus Weimar-Nordfriedhof Grab 56 (Opitz Nr. 52); Bernsteinperle aus Weingarten Grab 511 (Düwel 1994: 295; Roth/Theune 1995: Taf. 188 C).

Sieblöffel aus Oberflacht (Jänichen 1967: Taf. 46; Opitz Nr. 35).

39 Holzstab (Teil eines Webstuhls?) aus Neudingen Grab 168 (Opitz 1982: Abb. 4; Kat. Göttingen Nr. 32; Düwel 2001: 58). 

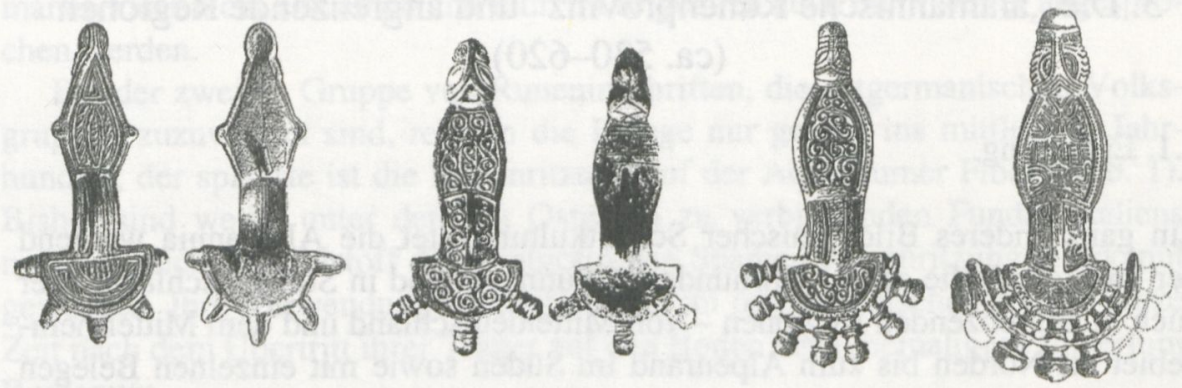

B 1

B 2

B 3

B 4
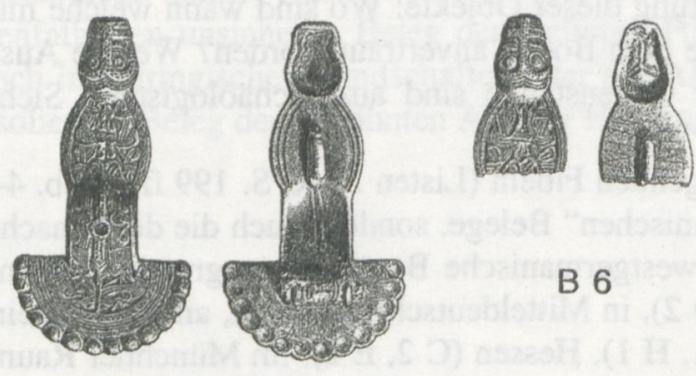

B 5

C 1

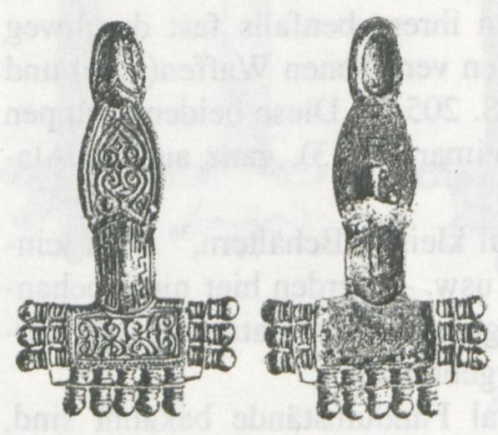

C 3

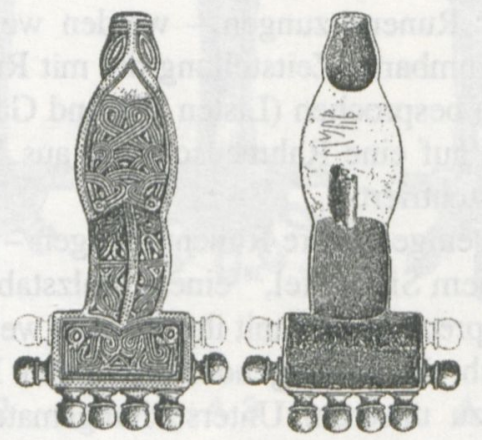

C 4

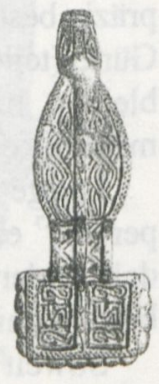

C 5

Abb. 5: Bügelfibeln mit Runeninschrift: Freilaubersheim (B 1), Weimar-Nordfriedhof Grab 57 (B 2), Schretzheim Grab 26 (B 3), Bezenye Grab 8 (B 4). Nordendorf II (B 5), Bad Ems (B 6); Dischingen (C 1), Herbrechtingen (C 3), Kaltenengers (C 4), Trossingen Grab 11 (C 5). (Maßstab $1: 3)$. Vgl. Listen B und C.

Abb. 6: Bügelfibeln mit Runeninschrift: Charnay (D 1), Beuchte Grab 1 (D 2), Aschheim Grab 166 (D 3), Donzdorf Grab 78 (D 4), Kirchheim u. Teck Grab 85 (D 5), Mertingen Grab 26 (D 6), Nordendorf I (D 7), Neudingen Grab 319 (D 8). (Maßstab 1: 3). Vgl. Liste 


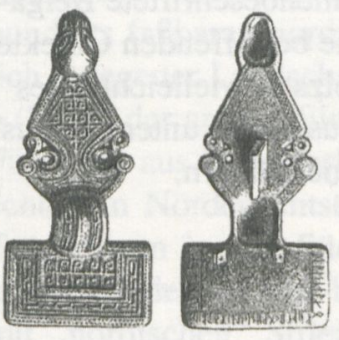

D 1
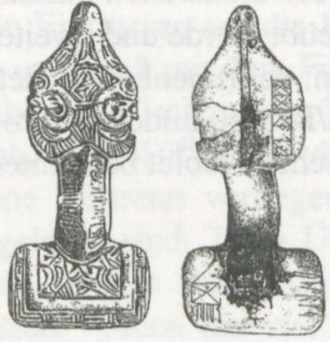

D 2

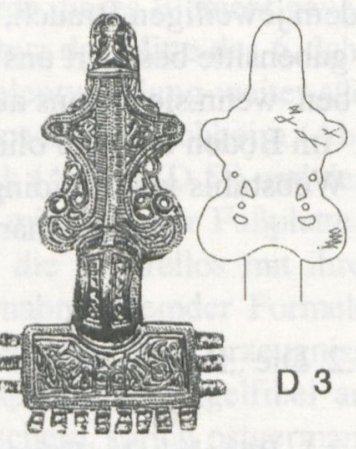

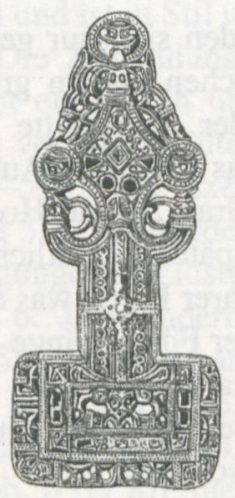

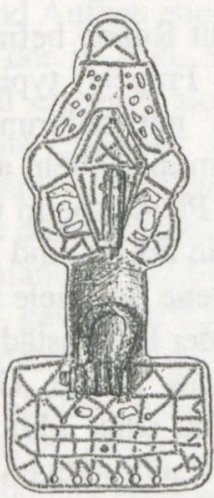

D 4

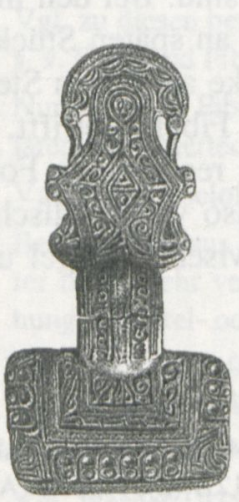

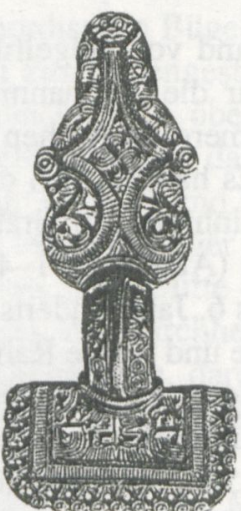

D 5

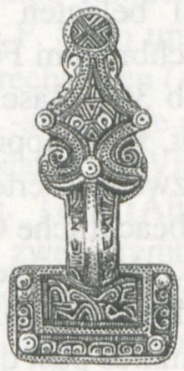

D 6
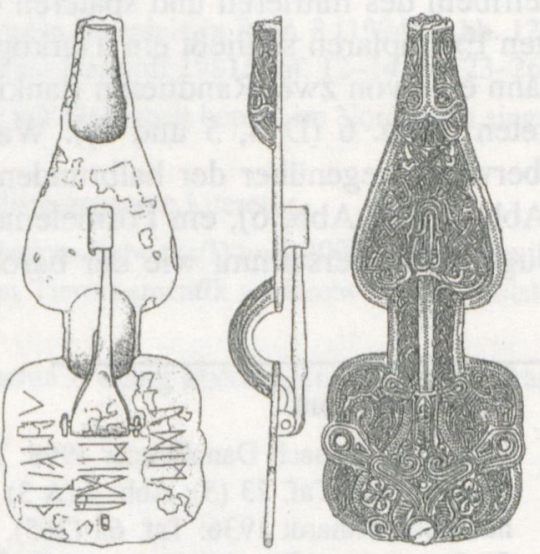

D 8 
aus Gräbern. Die Überlieferung der Runenritzungen verdanken wir demnach dem jeweiligen Brauch, den Toten Beigaben ins Grab mitzugeben. Diese Beigabensitte beschert uns selbstverständlich nur dann runenbeschriftete Beigaben, wenn sie erstens ausgeübt wurde und zweitens die betreffenden Objekte im Boden erhalten blieben; der runenbeschriftete Holzstab vielleicht eines Webstuhls von Neudingen/Baar40 bildet die große Ausnahme unter den aus dem alamannischen Gebiet bekannten Runenträgern.

\subsection{Die „Runenfibeln“}

\subsubsection{Bügelfibeln: Formen und Datierung}

Unter unserem Bestand von Bügelfibeln mit Runen befinden sich nur gerade vier Vertreter der für die Alamannia (und Francia) typischen und in großer Zahl belegten frühmerowingischen Form mit halbrunder Kopfplatte und gleichbreitem Fuß. Es handelt sich dabei um die Fibeln aus München-Aubing Grab 303, Basel-Kleinhüningen Grab 115, Pleidelsheim Grab 20 und Hohenstadt, Kr. Göppingen (Abb. 4 (A 1-4)). ${ }^{41}$ Die Fibeln sind späte, vermutlich bis ins zweite Viertel des 6. Jahrhunderts getragene Beispiele ihrer Form, was etwa die beachtliche Größe und reiche Rahmung der Hohenstädter Fibel (Länge 10,8 $\mathrm{cm}$ ), das mitgefundene Rautenfibelpaar des Basler Grabes und die drei goldenen Preßblechanhänger mit Abpressung einer Münze des Iustinianus I. (terminus post quem 526) im Aubinger Grab zu bestätigen scheinen.

An allen anderen Bügelfibeln finden sich - die Freilaubersheimer Fibel mit rhombischer Fußplatte (Abb. 5 (B 1)) ausgenommen - entweder ovale (Abb. 5) oder stark profilierte, barock ausgestaltete Fußplatten (Abb. 6), wie sie für Bügelfibeln des mittleren und späteren 6. Jahrhunderts üblich sind. Bei den meisten Exemplaren schließt ein Tierkopf das Fußende ab; erst an späten Stücken kann eine von zwei Randtieren flankierte, menschliche Maske an dessen Stelle treten (Abb. 6 (D 4, 5 und 7)). Was die Kopfplatten der Fibeln betrifft, so überwiegt gegenüber der halbrunden (Abb. 5 (B 1-6)) die rechteckige Form (Abb. 5 (C); Abb. 6), ein Formelement, das letztlich genauso von nordischen Bügelfibeln herstammt wie der barocke Fuß mit seinen zwischen Bügel und

40 Vgl. vorige Anm.

41 Abb. 4 (A 1) nach Dannheimer 1998: Taf. 34 (C 2 und 3); Abb. 4 (A 2) nach GieslerMüller 1992: Taf. 23 (5); Abb. 4 (A 3) nach U. Koch 2001: Taf. 12B (2); Abb. 4 (A 4) nach Schuchhardt 1936: Taf. 65 (265). Der Vollständigkeit halber sei erwähnt, daß ein fünftes, spätes Bügelfibelpaar mit gleichbreitem Fuß und halbrunder Kopfplatte in Weingarten Grab 511 (Roth/Theune 1995: Taf. 189 (3a und b)) mit der unten (3.5.6.) genannten Bernsteinperle mit Runeninschrift (Düwel 1994: 295) vergesellschaftet war. 
Fuß symmetrisch angebrachten Tierprotomen oder -köpfen. ${ }^{42}$ Bei der vermutlich jüngsten Fibel aus Neudingen (Abb. 6 (D 8)) wurde dieses Element gewissermaßen in die Fußplatte integriert. Zu diesen seit etwa der Mitte des 6. Jahrhunderts faßbaren nordischen Einflüssen auf die Fibelentwicklung weiter südlich gelegener Landschaften paßt, daß mit dem Fibelpaar aus Aschheim (Abb. 6 (D 3)), der großen Einzelfibel aus Kirchheim u. Teck (Abb. 6 (D 5)) und dem Fibelpaar aus Donzdorf (Abb. 6 (D 4) $)^{43}$ - alle drei mit barocker Fußplatte echte, im Norden entstandene Vertreter vorliegen ${ }^{44}$ die zweifellos mit ihren Trägerinnen in den Süden gelangt sind. Trotz Übernahme fremder Formelemente handelt es sich bei den übrigen Stücken um einheimische Erzeugnisse mit „nordischen“ Stileinflüssen. ${ }^{45}$ Auch die viel besprochene Bügelfibel aus Charnay in Burgund (Abb. 6 (D 1)) hat mit burgundischem, sprich ostgermanischem Fibelschmuck - bis auf die gerahmten Spiralhaken(?) - wenig gemeinsam und ist in Stil und Aufbau ebenfalls nordischen Bügelfibeln verpflichtet. ${ }^{46}$

Die Zeitstellung der in Abb. 5 und 6 zusammengestellten Bügelfibeln ist recht einheitlich und erstreckt sich vergleichsweise über wenige Jahrzehnte: Das vermutlich älteste Exemplar aus Freilaubersheim datierte F. Stein um ca. 520-560. ${ }^{47}$ Die Exemplare aus Schretzheim Grab 26 und Herbrechtingen (Abb. 5 (B 3, C 3)) werden durch mitgefundene Münzanhänger bzw. -abschläge nach Prägungen des Iustinianus I. (527-565) etwa in die Mitte oder das dritte Viertel des 6. Jahrhunderts gewiesen. ${ }^{48}$ Die Fibel aus Kirchheim u. Teck (Abb. 6 (D 5)) war unter anderem mit drei Münzanhängern, darunter zwei Tremissen des Iustinus II. (565-578), vergesellschaftet; ${ }^{49}$ ihre Trägerin verstarb demnach bereits im letzten Drittel des 6. Jahrhunderts. Die große Fibel aus Neudingen (Abb. 6 (D 8)), die bereits an späteste Bügelfibeln des Mainzer Raumes erinnert, ${ }^{50}$ mag als jüngste bereits der Zeit um 600 angehören.

42 Vgl. zu diesen beiden nordischen Formelementen Beispiele in RGA 8 [1994]: Abb. 123, s. v. Fibel und Fibeltracht (L. Jørgensen) und bei Haseloff 1981: Taf. 12-14 und 23-26.

43 Nur an dieser Fibel wurden die (drei) Runen mit Sicherheit bereits im Norden (in singulärer Tremoliertechnik) eingeritzt.

44 Vgl. dazu Haseloff 1981 und die in der Fundliste genannte Literatur.

45 Bei der Fibel aus Mertingen (Abb. 6 (D 6)) denken Babucke/Düwel 2000: 168 wegen ihrer nicht mehr verstandenen skandinavischen Tierornamentik zu Recht an eine Entstehung in Mittel- oder Süddeutschland.

46 Roth (RGA 4 [1981]: 373 s. v. Charnay) dachte - wenig überzeugend - an eine „fränkisch bestimmte Werkstatt Burgunds".

47 Stein 1987: $1395 \mathrm{f}$.

$48 \mathrm{Vgl}$. Werner 1935: 87 (Nr. 20 und 21).

49 Nau, in: Haseloff 1981: 724 f. und Taf. 94 (1-3).

50 Vgl. ein gutes Gegenstück (Länge 13,3 cm) als Einzelfund aus Dalsheim: Zeller 1994: Abb. 2. 
Die Datierung der mit Runen versehenen Bügelfibeln, d. h. deren Grablegungszeit, ist demnach relativ einheitlich und erstreckt sich höchstens über etwa sechs Jahrzehnte: Am ehesten dürften ihre Besitzerinnen im Zeitraum zwischen dem zweiten Viertel und den letzten Jahrzehnten bzw. dem Ende des 6. Jahrhunderts verstorben sein. Die Entwicklung der Bügelfibel, sowohl im alamannischen wie auch fränkischen Gebiet, ist demnach spätestens seit etwa der Mitte des 6. Jahrhunderts stark durch nordische Vorbilder und einzelne ihrer Formelemente beeinflußt.

\subsubsection{Klein- und Einzelfibeln: Formen und Datierung}

Die sogenannten Kleinfibeln, die seit dem 5. Jahrhundert als Paare einen Mantel oder Umhang verschlossen, werden im Laufe des späteren 6. Jahrhunderts durch größere, meist scheibenförmige Einzelfibeln abgelöst, die an der gleichen Stelle, am Hals oder auf der oberen Brust, und in gleicher Funktion getragen wurden. Dieser Wechsel des Mantelverschlusses vollzog sich selbstverständlich nicht von einem Jahrzehnt aufs andere. ${ }^{51}$

Unter den Hunderten älterer Kleinfibelpaare der zweiten Hälfte des 5. und der ersten Hälfte des 6. Jahrhunderts - vor allem Vogel- und andere Tierfibeln (Abb. 3) sowie frühe Scheiben- und S-Fibeln - findet sich kein einziges, mit Runen beschriftetes Exemplar.

$\mathrm{Zu}$ einer ersten Gruppe lassen sich einige teils entwickeltere, teils späte Granatscheibenfibeln mit Runenritzung zusammenstellen: kleinere Vertreter (Abb. 7 (E 2-5)) sind normalerweise - E 3 und E 4 ausgenommen - zusammen mit einer identischen oder einer S-Fibel gefunden worden, wogegen größere Exemplare (Abb. 7 (E 6 und 7)) zu den nachfolgenden Einzelfibeln gleicher Funktion gehören. Die ganze Reihe ist zeitlich etwa zwischen dem zweiten Viertel des 6. Jahrhunderts und der Zeit um 600 in den Boden gelangt, wie etwa ein Vergleich mit U. Kochs zeitlicher Einordnung der Granatscheibenfibeln der Nekropole von Schretzheim verrät. ${ }^{52}$ Die engzellige Fibel aus Soest Grab 106 (Abb. 7 (E 7)), die als einzige der Gruppe noch mit (auffallenderweise nicht als Runenträger benutzten) Bügelfibeln vergesellschaftet war, wird durch einen Münzanhänger mit Solidus des Iustinianus I. aus Ravenna (ca. 552-565) - in stark abgenutzter Filigranfassung - sicher ins letzte Drittel des 6. Jahrhunderts datiert. Bereits dieser Zeit teilt U. Koch, vermutlich vor allem der zuge-

51 Vgl. dazu Martin 1995.

52 U. Koch 1977: 58-64; zum Bülacher Exemplar (Abb. 7 (E 6)) vgl. auch Stein 1987: 1392 f. (ca. „560-600“). Vgl. jetzt die monographische Bearbeitung der Granatscheibenfibeln durch Vielitz 2003. 
hörigen Perlen wegen, auch die typologisch ältere Fibel zu, die in Schretzheim Grab 509 (Abb. 7 (E 3)) ohne paariges Gegenstück zutage kam. ${ }^{53}$

Filigran- und Preßblechscheibenfibeln sind zum größten Teil typische Einzelfibeln des 7. Jahrhunderts. Es überrascht deshalb nicht, daß von beiden Fibelgruppen bislang insgesamt nur drei Belege mit Runenritzung bezeugt sind. ${ }^{54}$ Die Filigranscheibenfibel aus dem württembergischen Balingen (Abb. 7 (F 1)) wie auch die ähnlich, aber weniger gekonnt dekorierte und aus dem billigeren Silber gefertigte aus Weißenburg (F 2) zählen mit ihrer geringen Größe (Durchmesser 4,3 bzw. 3,3 cm!) und „schlichten“ Verzierung zu den frühen Vertretern der Gruppe der Rundfibeln mit Mittelbuckel, die den Jahrzehnten vor und um 600 zuzuweisen ist. ${ }^{55}$ Ungefähr zeitgleich anzusetzen ist die bisher einzige Preßblechfibel mit Runenschrift aus Osthofen in Rheinhessen (Abb. 7 (H 1)). ${ }^{56}$

Runen weisen nur noch zwei weitere Serien von Klein- und Einzelfibeln auf. Zum einen sind dies die teils noch paarweise, teils - als Weiterentwicklung - bereits einzeln getragenen (und dann auch als Einzelstücke hergestellten) S-Fibeln (Abb. 8 (I 1-5)), ${ }^{57}$ zum andern eine Gruppe von Einzelfibeln, die im Umriß Scheibenfibeln ähneln und als Tierwirbelfibeln bezeichnet werden können (Abb. 8 (K 1-3)); ${ }^{58}$ eines der Vorbilder dieser Tierwirbelfibeln könnte die scheibenförmige S-Fibel (Abb. 8 (I 5)) gewesen sein, zu der ein qualitätvolleres, allerdings noch paarig getragenes Gegenstück anzuführen ist. ${ }^{59}$

53 Vgl. U. Koch 1977: 22 und 24 und Abb. 4; Tabelle 4 (Perlenkombination).

$54 \mathrm{Zu}$ den singulären Tierwirbelfibeln aus Chéhéry, deren goldenes Preßblech mit seinen Filigranauflagen jeweils Techniken der Filigran- und der Preßblechfibeln in sich vereinigt, vgl. Abb. 8 (K 1a und b).

55 Thieme 1978: 415-417 und 437 f. und Taf. 3 (4) (Gruppe I 2: rund, mit Mittelbuckel). Auf der Rückseite einer weiteren, ebenfalls relativ frühen Filigranscheibenfibel aus dem Mädchengrab von Gammertingen, in dem auch ein runenberitztes Büchschen aus Elfenbein zum Vorschein kam, bilden, ,runenähnliche Zeichen [...] möglicherweise [...] die Nachahmung einer Runen-Inschr[ift]“: (RGA 10 [1998]: 421 s. v. Gammertingen (K. Düwel)).

56 Vgl. Klein-Pfeuffer 1993: 17-21 und 134-139; nebst anderem spricht auch die an dieser Stelle (17 mit Anm. 103-105) diskutierte Vergesellschaftung einer der Parallelen der Osthofener Fibel mit einem späten Bügelfibelpaar vom „Typ Soest“ (nach Kühn 1974: 1121 und Taf. 308 (9) [Wolfskehlen Grab 2]) für eine Datierung der Osthofener Fibel und ihrer Gegenstücke noch in die Zeit um 600; vgl. dazu auch U. Koch 2001: 160.

Wie etwa der Befund der Nekropolen Straubing-Bajuwarenstraße (Geisler 1998, Taf. 347 und 348) und München-Aubing (Dannheimer 1998: Taf. 98 (15-22)) verrät, gehörten I 1-3 und offensichtlich auch I 4 - nur bei I 2 wurde noch das Pendant angetroffen ursprünglich zu Fibelpaaren, wogegen I 5 eine echte Einzelfibel darstellen dürfte.

In Chéhéry handelt es sich ausnahmsweise noch um ein Paar (fast) identischer Fibeln.

59

Dannheimer 1962: Taf. 13 (3 und 5). 

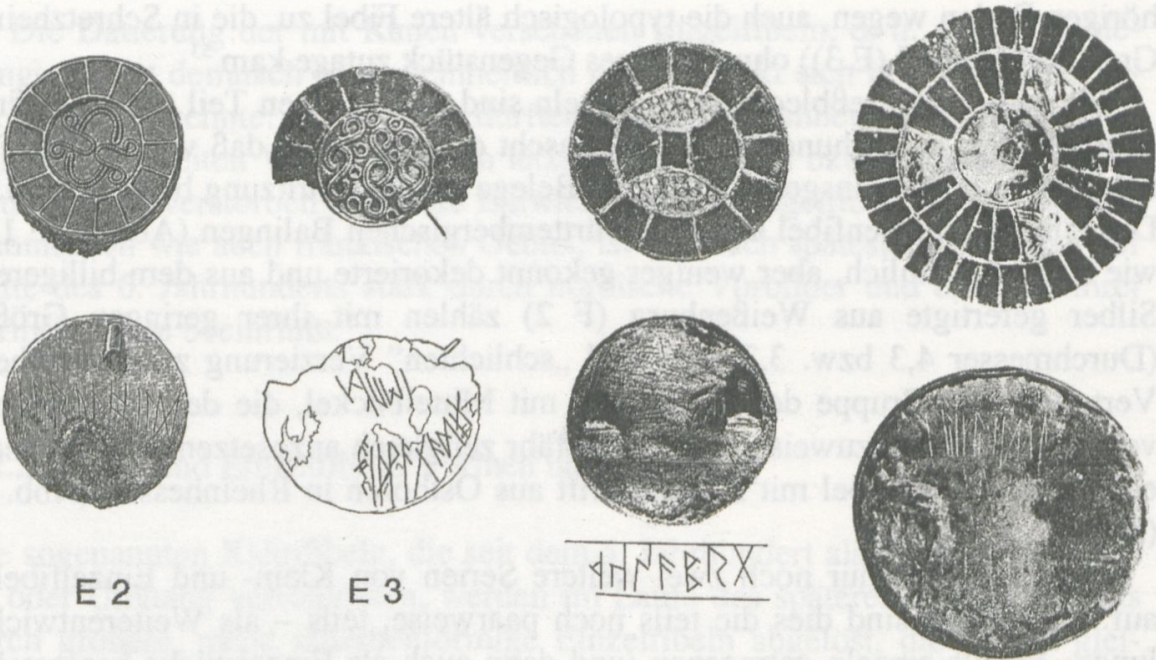

E 5

E 6
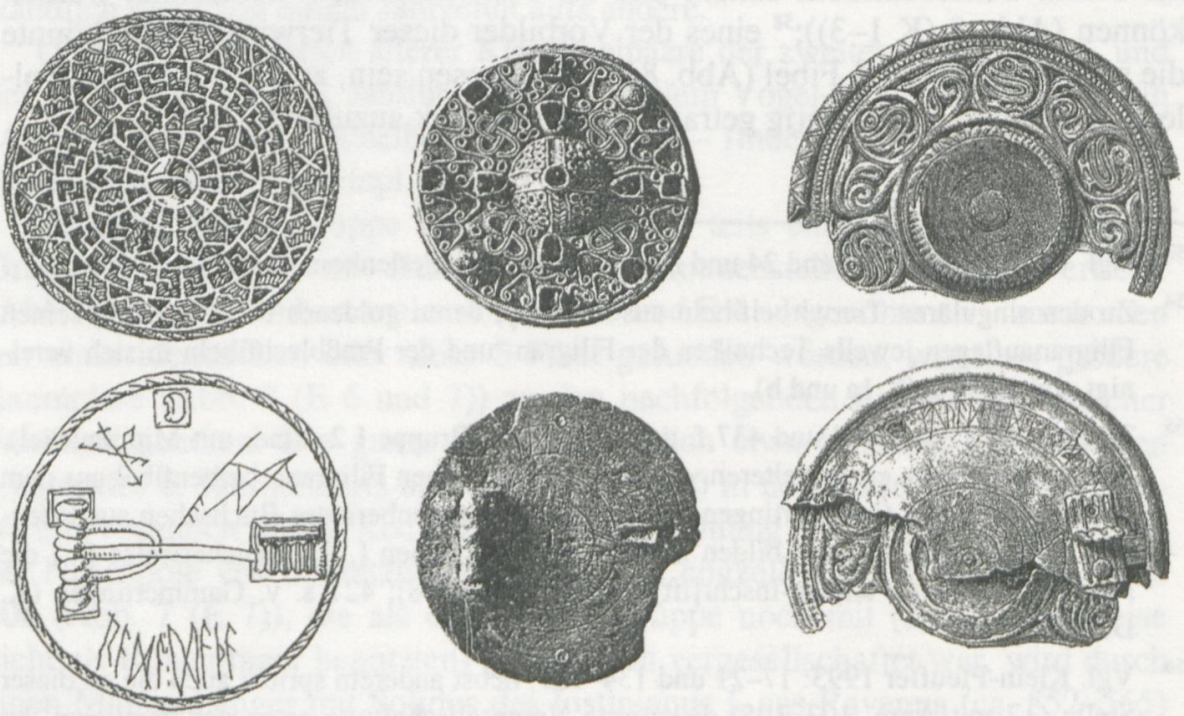

E 7

F 1

H 1

Abb. 7: Granatscheibenfibeln, Filigran- und Preßblechscheibenfibel mit Runen: Friedberg Grab 10 (E 2), Schretzheim Grab 509 (E 3), Öttingen Grab 13 (E 5), Bülach Grab 249 (E 6), Soest Grab 106 (E 7); Balingen (F 1); Osthofen (H 1). (Maßstab 2: 3). Vgl. Listen E-H.

Abb. 8: S-Fibeln und Tierwirbelfibeln mit Runen: Szentendre Grab 33 (I 1), Weingarten Grab 179 (I 2), Hailfingen Grab 406 (I 3), Weingarten Grab 272 (I 4), Schongau Grab 33 (I 5); Chéhéry (K 1), München-Aubing Grab 163 (K 2), München-Aubing Grab 383 (K 3). 

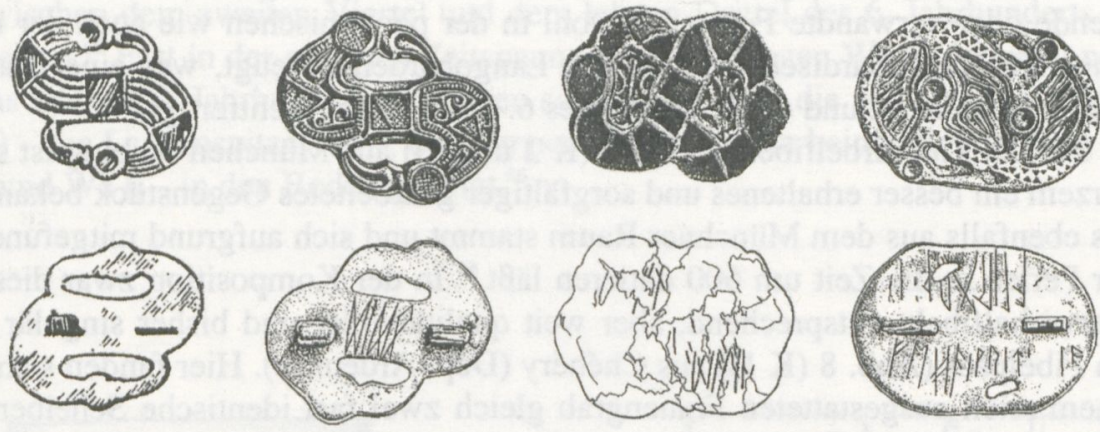

11

12

13

14
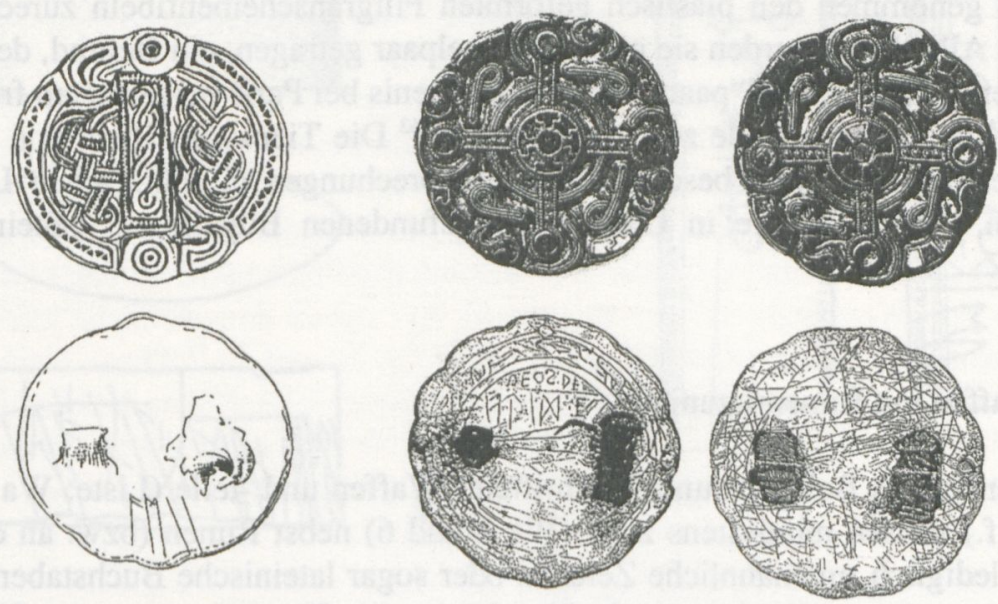

15

K 1
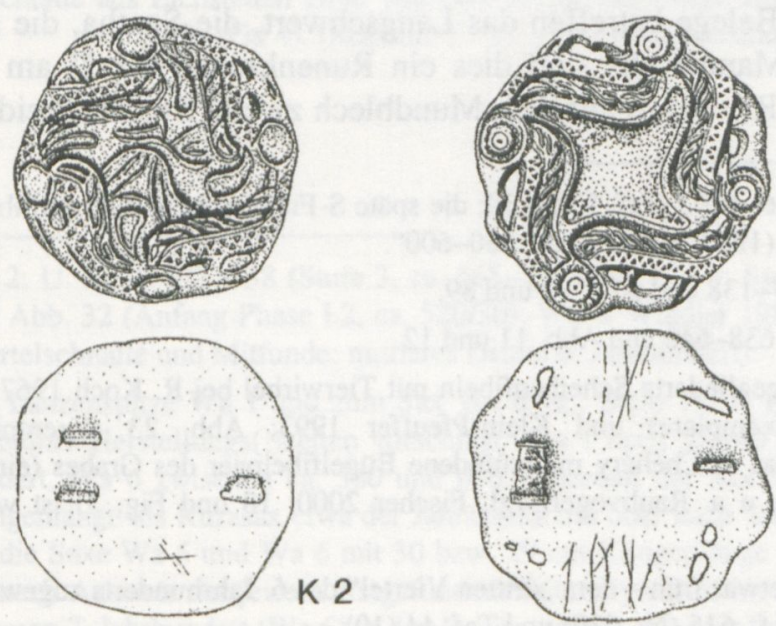

$\mathrm{K} 2$

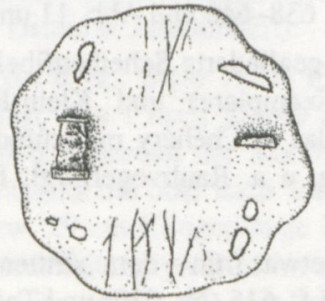

K 3 
Was die Zeitstellung der S-Fibeln (Abb. 8 (I 1-3)) angeht, so sind entsprechende oder verwandte Formen sowohl in der pannonischen wie auch der beginnenden langobardischen Phase der Langobarden bezeugt, was eine Datierung in das zweite und dritte Viertel des 6 . Jahrhundert rechtfertigt. ${ }^{60}$

$\mathrm{Zu}$ den Tierwirbelfibeln (Abb. 8 (K 2 und 3)) aus München-Aubing ist seit kurzem ein besser erhaltenes und sorgfältiger gearbeitetes Gegenstück bekannt, das ebenfalls aus dem Münchner Raum stammt und sich aufgrund mitgefundener Perlen in die Zeit um 600 datieren läßt. ${ }^{61}$ In der Komposition zwar diesen Tierwirbelfibeln entsprechend, aber weit qualitätvoller und bisher singulär ist ein Fibelpaar (Abb. 8 (K 1)) aus Chéhéry (Dép. Ardennes). Hier fanden sich in einem reich ausgestatteten Frauengrab gleich zwei fast identische Scheibenfibeln aus Goldblech mit Filigranauflagen und Cloisonnéeinlagen, die man im Grunde genommen den plastisch geformten Filigranscheibenfibeln zurechnen könnte. Allerdings wurden sie noch als Fibelpaar getragen, ein Befund, der mit dem wenig älteren Fibel"paar" der in Saint-Denis bei Paris beigesetzten fränkischen Königin Arnegunde zu vergleichen ist. ${ }^{62}$ Die Tierwirbelfibeln von Chéhéry besitzen erheblich bescheidenere Entsprechungen in fränkischen Landschaften, ${ }^{63}$ wo auch die in Chéhéry mitgefundenen Bügelfibeln beheimatet sind. ${ }^{64}$

\subsection{Waffen mit Runenritzungen}

Von den sieben Belegen runenbeschrifteter Waffen und -teile (Liste: Wa 1-7, S. 205 f.) weisen mindestens zwei (Wa 4 und 6) nebst Runen (bzw. an deren Stelle) lediglich runenähnliche Zeichen oder sogar lateinische Buchstaben auf. Hier interessieren allerdings nicht Vergleiche mit Runenritzungen an Fibeln, sondern nur die Verbreitung der „Runenwaffen“ und deren Datierung.

Gleich drei der Belege betreffen das Langschwert, die Spatha, die angesehenste Waffe des Mannes: Es sind dies ein Runenkreuz (Wa 2) am Ansatz einer Klinge sowie Ritzungen auf dem Mundblech zweier Spathascheiden (Wa

60 Vgl. etwa Bierbrauer 1993: Taf. 9 und 10; die späte S-Fibel Abb. 8 (I 4) und ihre Parallelen datierte Stein (1987: 1394 f.) ca. ,560-600“.

61 Reimann 1997: 137-138 und Abb. 87 und 89.

62 Martin 1995: Abb. 638-640 und Abb. 11 und 12.

63 Vgl. etwa ähnlich gegliederte Scheibenfibeln mit Tierwirbel bei R. Koch 1967: Taf. 87 (5) (gegossene Exemplare) und Klein-Pfeuffer 1993; Abb. 23 (Exemplare aus Preßblech); auch das in Chéhéry mitgefundene Bügelfibelpaar des Grabes (eine davon mit Ritzverzierung, u a. Raubvogel, vgl. Fischer 2000: 18 und Fig. 3) ist wohl eine fränkische Arbeit.

Besprochen und - etwas früh - dem ,dritten Viertel“ des 6. Jahrhunderts zugewiesen bei A. Koch 1998: 315 f., 615 (Nr. 239) und Taf. 44 (10). 
3 und 4, Abb. 9 (1)). Alle drei lassen sich durch Mitfunde ungefähr der Zeit zwischen dem zweiten Viertel und dem letzten Drittel des 6. Jahrhunderts zuweisen. ${ }^{65}$ Fast in der gleichen Zeitspanne, der man wegen Wa 6 vielleicht noch das frühere 7. Jahrhundert zurechnen sollte, sind auch die anderen Waffen(teile) - die Lanzenspitze Wa 1, der Kurzsax Wa 7 und die beiden Schmalsaxe Wa 5 und Wa 6 - in den Boden gelangt. ${ }^{66}$
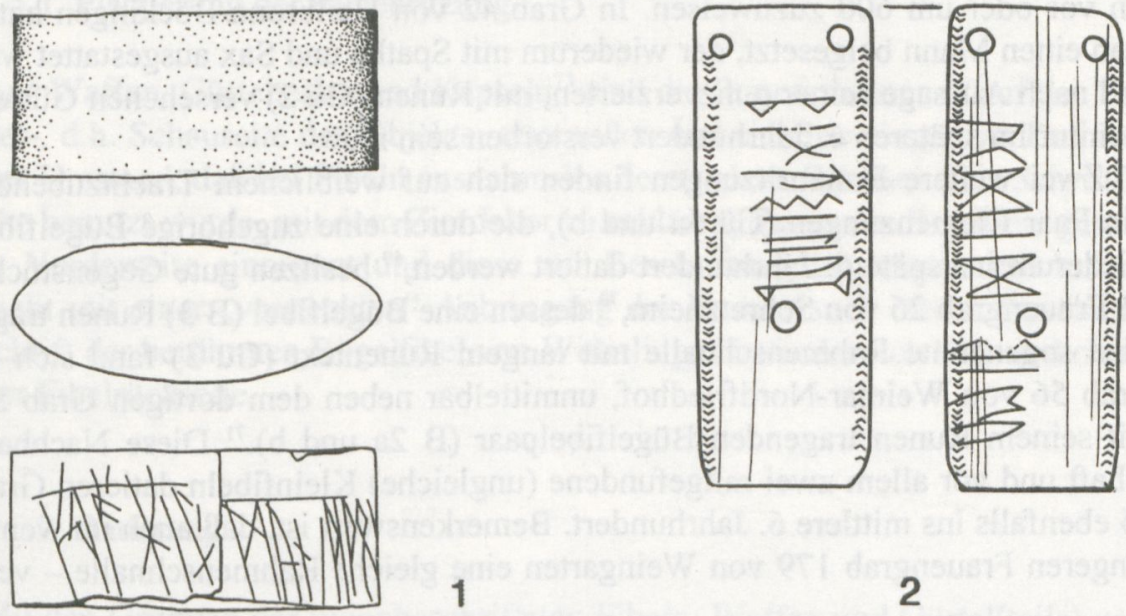

Abb. 9: Runen auf Waffen(teil) bzw. auf Gürtelbeschlag aus Silberblech: Mundblech einer Spathascheide aus Eichstetten Grab 186 (Wa 3); Riemenzunge aus Niederstotzingen Grab 3a (Gü 4). (Maßstab $3: 4)$. Vgl. Listen Wa und Gü.

65 Wa 2: U. Koch 1977: 38 (Stufe 3, ca. 565-590/600); Wa 3: Sasse 2001: 124, 138, 152 und Abb. 32 (Anfang Phase I.2, ca. 520/30); Wa 4: Windler 1989: 191 und Abb. 18 (1) (Gürtelschnalle und Mitfunde; mittleres Drittel 6. Jahrhundert).

Zur Lanzenspitze Wa 1 und zum Sax Wa 6 vgl. Stein 1987: 1397-1400, die folgende ungefähre Herstellungs(!)zeiten vorschlägt: Wa 1 nach 550/60 bis evtl. frühes 7 . Jahrhundert, Wa 6 zwischen ca. 560 und 600. Während der Sax Wa 7 mit seinen $24 \mathrm{~cm}$ Klingenlänge als Kurzsax etwa der Jahrzehnte um oder nach 550 anzusprechen ist, stellen die Saxe Wa 5 und Wa 6 mit 30 bzw. 29 cm Klingenlänge leichte Schmalsaxe dar, die nach Ausweis der jeweils mitgefundenen Gürtelgarnitur im späteren 6. (Wa 5) bzw. früheren 7. Jahrhundert (Wa 6) in den Boden gelangt sein werden. 


\subsection{Gürtel(teile) mit Runen}

Auch von den sechs mit Runen versehenen Gürtelteilen (Liste Gü 1-6, S. 206 f.) stammen drei aus Spathagräbern: Die Pforzener Gürtelschnalle (Gü 1) gehört wie eine verwandte Schnalle, die mit dem Runen(?) tragenden Mundblech von Bopfingen (Wa 4) vergesellschaftet war, ins dritte Viertel des 6. Jahrhunderts. ${ }^{67}$ Die beidseits mit Runen bedeckte Riemenzunge aus u-förmig gefaltetem Silberblech (Gü 4) ${ }^{68}$ des Grabes 3a von Niederstotzingen (Abb. 9 (2)) ist wegen ihrer Mitfunde (Spatha mit strichtauschiertem Knauf, Sax usw.) - sein Besitzer war der Erstbestattete des Dreiergrabes (3a-c) - den Jahrzehnten vor oder um 600 zuzuweisen. In Grab 42 von Heilbronn-Böckingen hatte man einen Mann beigesetzt, der wiederum mit Spatha und Sax ausgestattet war und nach Aussage seiner punzverzierten, mit Runen (Gü 2) versehenen Gürtelgarnitur im späteren 6 . Jahrhundert verstorben sein muß.

Zwei weitere Runenritzungen finden sich auf weiblichem Trachtzubehör: Ein Paar Riemenzungen (Gü 5a und b), die durch eine zugehörige Bügelfibel wiederum ins späte 6 . Jahrhundert datiert werden, ${ }^{69}$ besitzen gute Gegenstücke im Frauengrab 26 von Schretzheim, ${ }^{70}$ dessen eine Bügelfibel (B 3) Runen trägt. Eine sogenannte Rahmenschnalle mit langem Runentext (Gü 3) fand sich in Grab 56 von Weimar-Nordfriedhof, unmittelbar neben dem dortigen Grab 57 mit seinem Runen tragenden Bügelfibelpaar (B 2a und b). ${ }^{71}$ Diese Nachbarschaft und vor allem zwei mitgefundene (ungleiche) Kleinfibeln datieren Grab 56 ebenfalls ins mittlere 6 . Jahrhundert. Bemerkenswert ist, daß auch im wenig jüngeren Frauengrab 179 von Weingarten eine gleiche Rahmenschnalle - ver-

67 Windler 1989.

68 Die Riemenzunge Gü 4 kann, entgegen bisheriger Ansicht, nicht aus dem Mundblech einer Spatha sekundär zurecht geschnitten worden sein (Düwel 2001: 67). Dagegen sprechen die Maße des Bleches (2,3 cm breit, 12,7 cm lang, laut Paulsen 1967: Abb. 20), aber im Grunde genommen auch die Faltung in der Mitte der Gesamtlänge. Auch spricht nichts gegen, sondern manches für eine Anbringung der Runen nach Fertigstellung, d.h. nach Faltung und Vernietung der Riemenzunge, sind doch die Runenzeichen auf den beiden Seiten unterschiedlich orientiert und nehmen beide Male auf jeweils einen Niet Rücksicht. Dass etwa die Niete wie auch der Punzdekor der Blechkanten die Runenzeichen beschädigen würden (H. Jänichen, in: Paulsen 1967: 45), ist nicht erwiesen.

69 Paret 1935-38: Taf. 34 (1).

70 U. Koch 1977: Taf. 11.

71 Ein weiterer "quadratischer Schnallenrahmen, $3,8 \mathrm{~cm}$ “ fand sich im benachbarten Grab 55 (Schmidt 1970: 84). 
mutlich Aufhängeplatte einer Gehängetasche ${ }^{72}$ - wiederkehrt, zusammen mit der runenbeschrifteten S-Fibel I 2.

\subsection{Ergebnisse}

Welche Aussagen über die mit Runen beschrifteten Gegenstände des 6. Jahrhunderts und deren „Besitzer“ sind aus archäologischer Sicht möglich?

\subsubsection{Platzierung der Runenritzung}

Auf Waffen, Gürtelteilen und Kapseln ${ }^{73}$ sind die Runen meistens ${ }^{74}$ auf der Vorder-, d.h. Schauseite des Objekts, also außen und sichtbar eingeritzt. Damit ist der Umstand, daß bei Fibeln ausnahmslos deren glatte Rückseite als Schriftfläche benutzt wurde, mit dem Zierdekor zu erklären, das in der Regel die gesamte Vorderseite einnimmt und diese zur Beschriftung ungeeignet macht, und nicht mit einer ,versteckten“ Anbringung der Runen; auch die lateinische Inschrift der berühmten Bügelfibel von Wittislingen befindet sich bekanntlich auf der Fibelrückseite.

\subsubsection{Datierung}

Mit den Gruppen der runenbeschrifteten Fibeln, Waffen und Gürtel(teile) wurden die häufigsten und am besten datierbaren Objekte mit Runenritzung erfaßt. Was deren Zeitstellung betrifft, so kann nach obiger Besprechung kein Zweifel daran bestehen, daß die kontinentalgermanische Sitte der Runenritzung, die extrem stark auf Süddeutschland konzentriert ist, etwa kurz vor oder um die Mitte des 6. Jahrhunderts einsetzt und bereits in der Zeit um 600 wieder verschwindet.

$\mathrm{Zu}$ den ältesten Belegen dürften Runen auf frühen Bügelfibeln wie $\mathrm{A} 1$ und 2 oder B 1-4 zählen. Es macht den Anschein, daß die Belege aus dem männlichen Bereich, d.h. Waffen und Gürtelteile, im Vergleich zur zeitlichen Verteilung des Fibelbestandes mehrheitlich etwas später einsetzen. Dennoch läßt sich

72 Sie lag zusammen mit weiteren Objekten am linksseitigen Gehänge im Kniebereich der Toten (Roth/Theune 1995: Abb. 45).

73 Vgl. etwa die Kapseln aus Arlon (K.-J. Nr. 146), Schretzheim Grab 26 (K.-J. Nr. 157, vergesellschaftet mit der Runenfibel B 3) und das Elfenbeinbüchschen aus dem Mädchengrab von Gammertingen (K.-J. Nr. 161). 


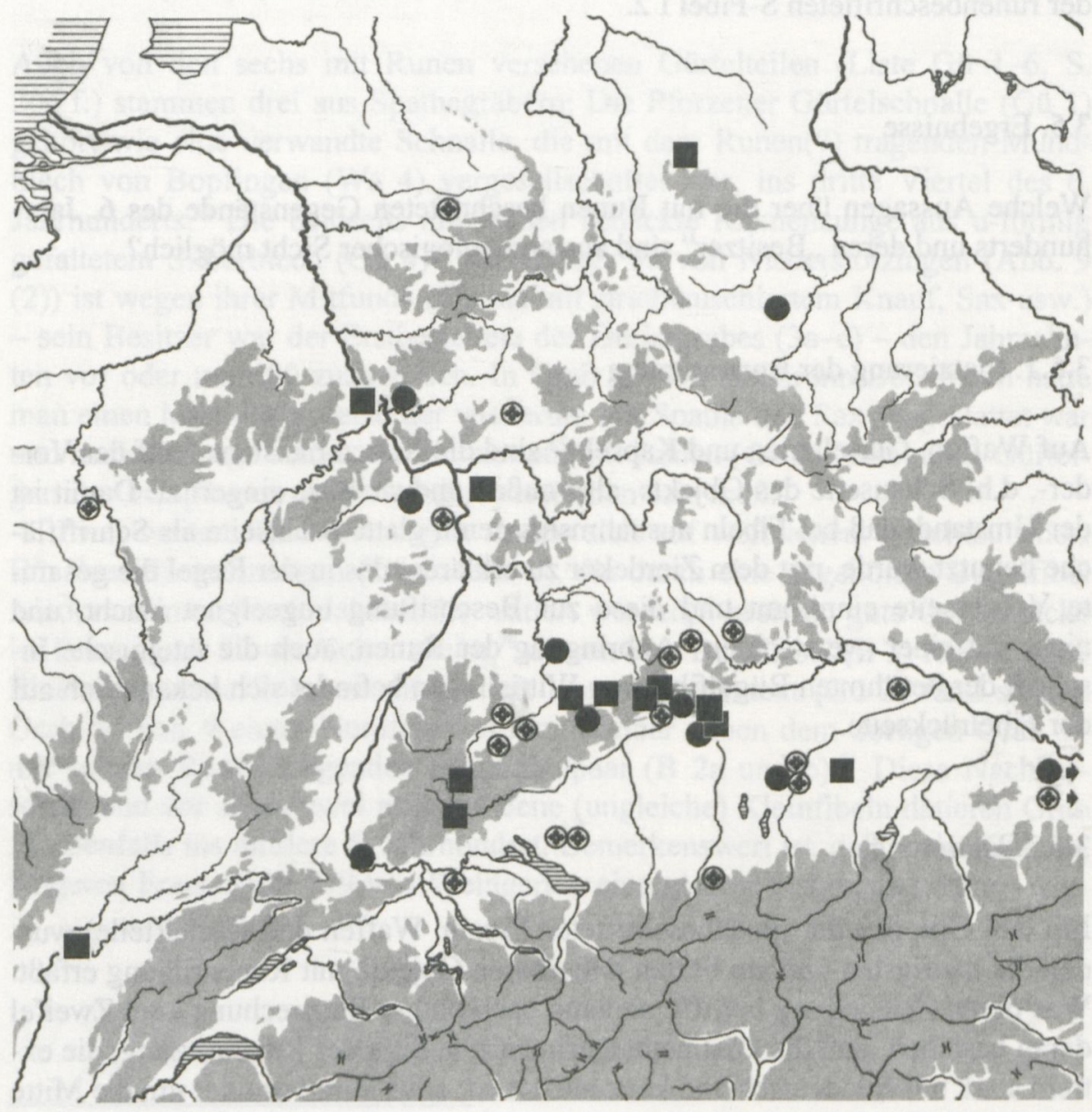

Abb. 10: Verbreitung der mit Runen beschrifteten Bügelfibeln mit halbrunder Kopfplatte (Punkt) bzw. mit rechteckiger Kopfplatte (Quadrat) sowie der Klein- und Einzelfibeln (Rosette im Kreis). Vgl. Listen A-K. 


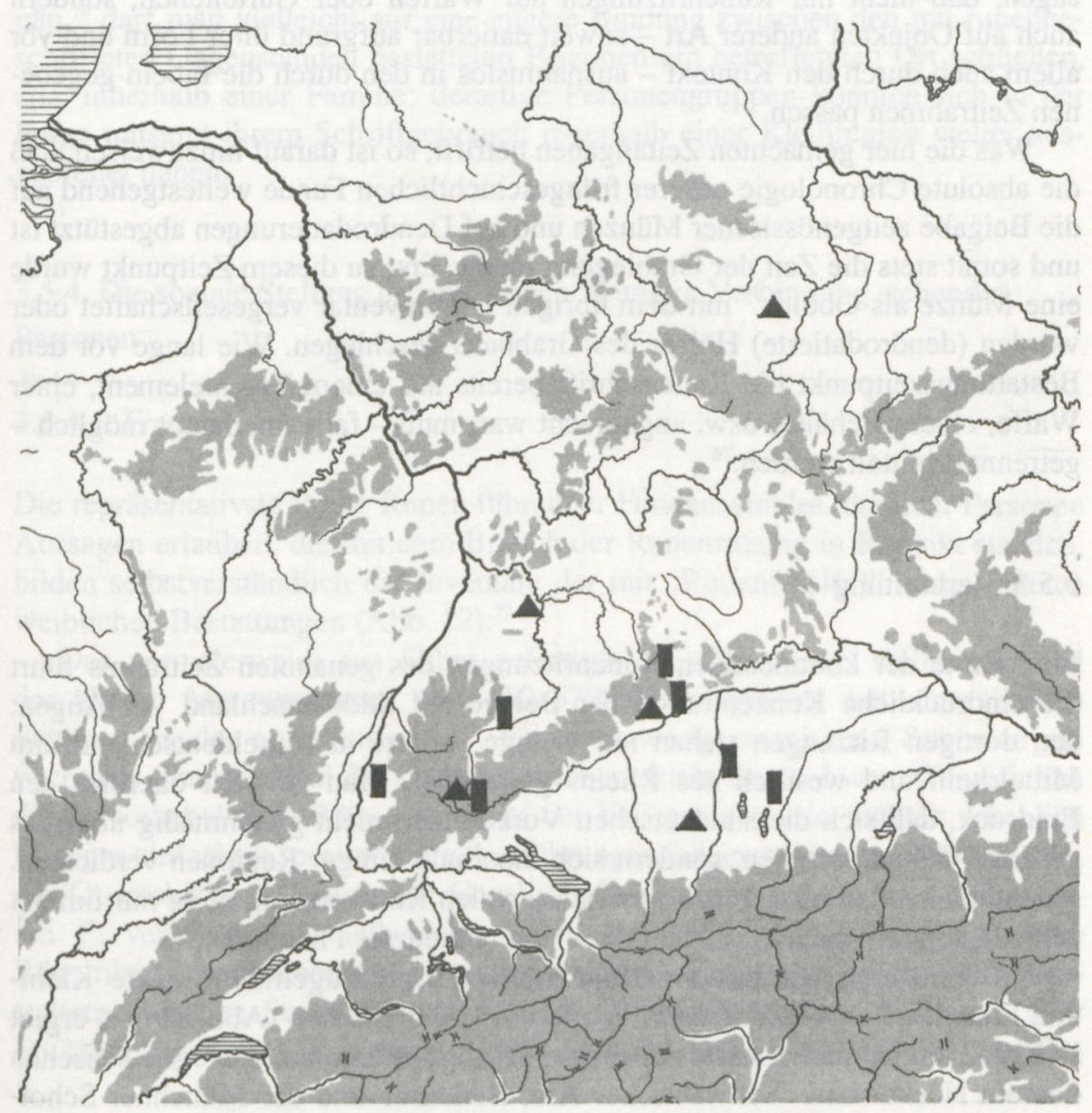

Abb. 11: Verbreitung der mit Runen versehenen Waffen- und Gürtelteile. Vgl. Listen Wa und Gü. 
sagen, daß nicht nur Runenritzungen auf Waffen oder Gürtelteilen, sondern auch auf Objekten anderer Art - soweit datierbar aufgrund ihrer Form und vor allem auch durch den Kontext - ausnahmslos in den durch die Fibeln gegebenen Zeitrahmen passen.

Was die hier gemachten Zeitangaben betrifft, so ist darauf hinzuweisen, daß die absolute Chronologie unserer frühgeschichtlichen Funde weitestgehend auf die Beigabe zeitgenössischer Münzen und auf Dendrodatierungen abgestützt ist und somit stets die Zeit der Grablegung meint: Erst zu diesem Zeitpunkt wurde eine Münze als Obolus ${ }^{75}$ mit dem übrigen Grabinventar vergesellschaftet oder wurden (dendrodatierte) Hölzer des Grabbaus geschlagen. Wie lange vor dem Bestattungszeitpunkt die Runenschrift bereits auf einem Trachtelement, einer Waffe, einem Behälter usw. angebracht war, muß - falls überhaupt möglich getrennt ermittelt werden. ${ }^{76}$

\subsubsection{Verbreitung}

Eine Karte der kontinentalen Runenritzungen des genannten Zeitraums führt die eindrückliche Konzentration der Belege auf Süddeutschland vor Augen; den dortigen Ritzungen stehen nur wenige weitere in Mitteldeutschland, am Mittelrhein und westlich des Rheins gegenüber. Man gewinnt überdies den Eindruck, daß sich die süddeutschen Vorkommen nicht gleichmäßig über das gesamte Gebiet verteilen, sondern sich innerhalb einiger Regionen verdichten. Jedenfalls handelt es sich bei der kontinentalen Runenritzung nicht nur um ein zeitlich, sondern auch räumlich relativ eng begrenztes Phänomen.

Differenzieren wir bei den Runenträgern nach Bügelfibeln sowie Kleinund Einzelfibeln (Abb. 10) bzw. Waffen- und Gürtelteilen (Abb. 11), so ergibt sich, daß am Mittelrhein fast nur Fibeln beschriftet wurden, wogegen zwischen oberem Neckar bzw. Schwäbischer Alb, Bodensee und der Münchner Schotterebene alle wichtigen Objektkategorien vertreten sind, auf denen Runenritzungen angebracht wurden. Anders formuliert: Fibeln sind offensichtlich überall als Runenträger ausgewählt worden, Waffen- und Gürtelteile fast ausschließlich zwischen Neckar und Isar.

Gut belegt sind im Süden die Region um die Donauquellen einerseits und Bayerisch-Schwaben andererseits, sowie der Raum um München. Aus der räumlichen Nachbarschaft, die zwischen runenführenden Bestattungen eines

75 Als Schmuck getragene Münzen liefern demgegenüber nur einen Terminus post quem „Zweiten Grades“.

76 In diesem Zusammenhang sei auf den Befund der Bügelfibel von Beuchte (D 2) hingewiesen, auf der die Runen offensichtlich erst nach einer längeren Abnutzungszeit der Fibel, d.h. vermutlich „kurz vor der Niederlegung als Grabbeigabe“ (Düwel 2001: 18) angebracht wurden. Weitere Beobachtungen in dieser Frage wären erwünscht. 
Friedhofs beobachtet wurde, in Weimar-Nordfriedhof ${ }^{77}$ und Pforzen im Allgäu, ${ }^{78}$ darf man vielleicht auf eine engere Bindung zwischen den mit runenbeschrifteten Gegenständen bestatteten Personen am betreffenden Ort schließen, z.B. innerhalb einer Familie; derartige Personengruppen könnten sich in der Folge mitsamt ihrem Schriftgebrauch innerhalb einer Kleinregion weiter ausgebreitet haben.

\subsubsection{Die soziale Stellung der mit Runenritzung in Verbindung stehenden} Personen

\subsubsection{Frauen}

Die repräsentativste Reihe Runen führender Fundensembles, die über Personen Aussagen erlauben, die mit dem Brauch der Runenritzung in Kontakt standen, bilden selbstverständlich die Inventare der mit „Runenfibel(n)“ ausgestatteten weiblichen Bestattungen (Abb. 12): ${ }^{79}$

Das normalerweise aus Silber gefertigte Bügelfibel(paar) stellte während der älteren Merowingerzeit (ca. 450-570/80), zusammen mit einer breiten Schärpe, an der es befestigt war, bei allen westgermanischen Stämmen ein wichtiges Statussymbol der Damen der Oberschicht dar und war offensichtlich dieser vorbehalten. ${ }^{80}$ Wäre dies nicht der Fall gewesen, so müßten erheblich häufiger einfachere, preiswertere Ausführungen bekannt sein, die von weiteren, der Oberschicht nacheifernden Gesellschaftsschichten verwendet worden wären. Es verwundert deshalb nicht, daß in der Gruppe der Gräber, deren Tote Bügelfibeln mit Runenritzung besaßen (Abb. 12 oben), sich etliche gut ausgestattete Inventare finden, die unter anderem mehrere goldene Schmuck- oder Münzanhänger aufweisen und daneben auch durch reichliche Geräte- und Ge-

77 Schmidt 1970: Abb. 12 (Gräber 55, 56, 57).

78 Babucke 1999b: 125 und Abb. 3 (Gräber 239, 255). Auch im großen Friedhof von Hailfingen sind die beiden Runenritzungen I 3 und Wa 6 in zwei nur $15 \mathrm{~m}$ voneinander entfernten Gräbern gefunden worden, doch könnten derartige Nachbarschaften, abgesehen vom eindeutigen Befund in Weimar-Nordfriedhof (vgl. vorige Anm.), auch eine Folge der nur kurzfristigen „Runenmode“ bei mehr oder weniger zeitgleichen und somit im Friedhof benachbart beigesetzten Bestattungen sein.

79 Zur Tabelle Abb. 12: Bei kompletten Bügelfibelpaaren war, bis auf Ausnahmen (A 1, B 2, C 1), jeweils nur eine der Fibeln mit Runen versehen. Was die Mitfunde der Gräber betrifft, so sind nur solche aus Edelmetall bewußt hervorgehoben, bei den übrigen wird durch einfache Kreuze die jeweilige Anzahl vermerkt. Ob einige wenige Inventare nicht ganz vollständig überliefert sind (so etwa vermutlich C 1), kann hier nicht diskutiert werden.

80

Vgl. dazu und zum folgenden Martin 1995. 


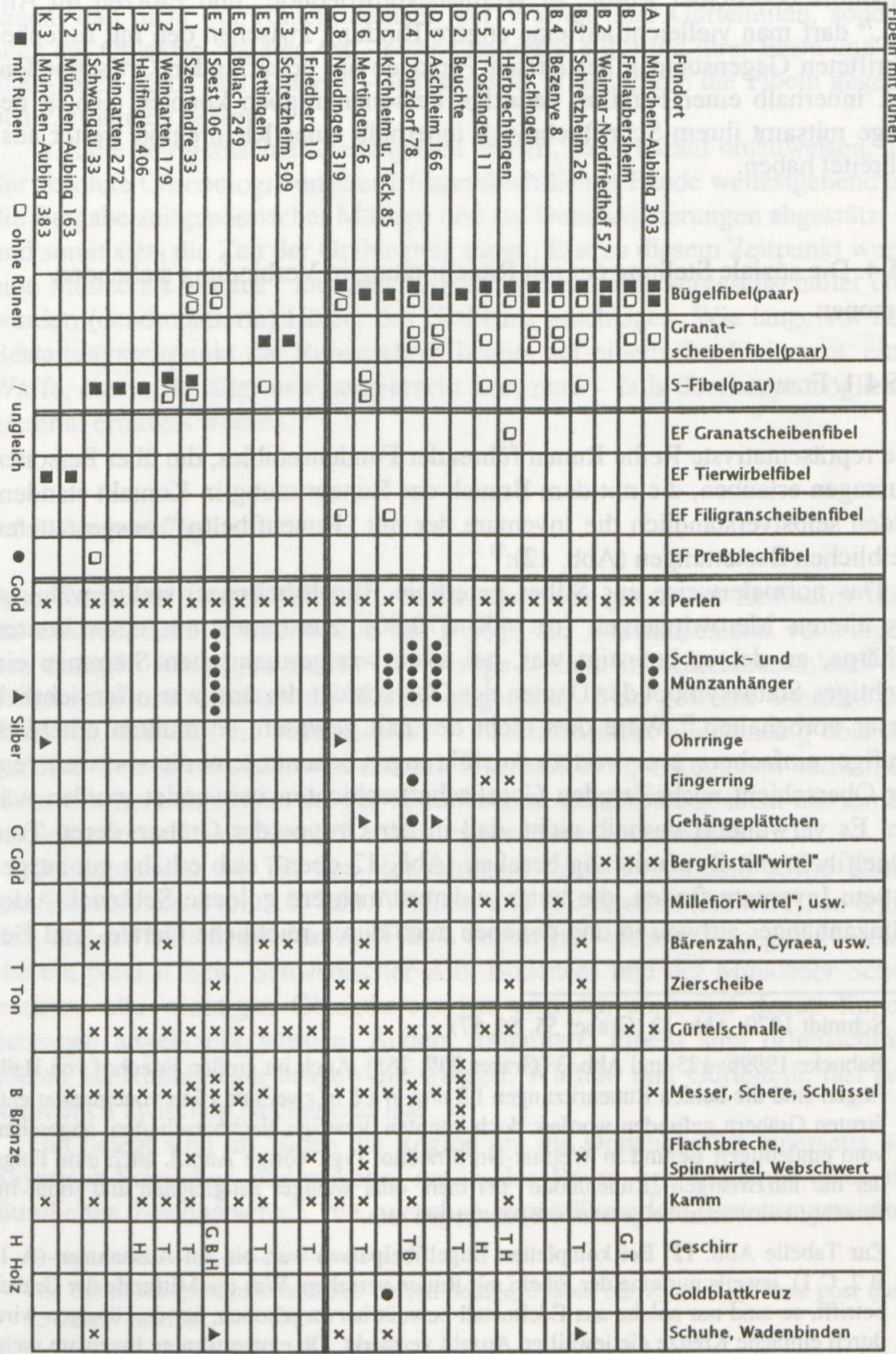

Abb. 12: Die Ausstattung der geschlossenen Grabinventare der mit Runenfibeln beigesetzten Frauen; zu den Angaben am linken Tabellenrand vgl. die Listen A-K. 
schirrbeigabe auffallen. Vielleicht wird hier, wenigstens teilweise, eine fremde, tendenziell reichhaltigere Beigabensitte spürbar, gehören doch alle drei sicher nordischen Bügelfibeln (D 3-5) zu diesen reichhaltigeren Inventaren.

Bei der zweiten Gruppe aussagekräftiger Inventare ist die Runenritzung jeweils auf einer Kleinfibel oder einer Einzelfibel angebracht (Abb. 12 unten). Nur in zwei dieser zwölf Gräber waren auch Bügelfibeln vorhanden, aber trotz größerer „Schreibfläche“ - nicht als Runenträger benutzt worden. Daß Bügelfibeln in diesen Inventaren fast gänzlich fehlen, geht wohl weitgehend auf die mehrheitlich jüngere Zeitstellung dieser Gräber, möglicherweise auch zum Teil auf eine niedrigere soziale Stellung der betreffenden Bestattungen zurück. Die Sitte, Fibeln rückseitig mit Runen zu versehen, überdauert jedenfalls die Bügelfibel"mode" nur für kurze Zeit. Den drei echten (runenlosen) Einzelfibeln, die in der ersten Gruppe mit Bügelfibeln vergesellschaftet sind, stehen nämlich in der zweiten nur gerade vier Runen tragende Einzelfibeln der Jahrzehnte vor und um 600 gegenüber, die zu den spätesten Objekten mit „kontinentaler" Runenritzung gehören.

\subsubsection{Männer}

Für zehn der mit Runen versehenen Waffen- und Gürtelteile ist der Grabkontext überliefert (Wa 1-7; Gü 1, 2 und 4). Es ist bemerkenswert, daß in sieben, wahrscheinlich sogar acht dieser Männergräber eine Spatha zum Vorschein kam (Wa 2-5 und vermutlich auch Wa 1; Gü 1, 2 und 4). Da die Spatha - im 6. Jahrhundert ausgeprägter noch als danach - nur einer auch sonst besser ausgestatteten Minderheit des männlichen Bevölkerungsteils ins Jenseits mitgegeben wurde ${ }^{81}$ gehört Runenritzung und -brauchtum auch beim männlichen $\mathrm{Ge}$ schlecht zur gehobenen Bevölkerungsschicht. Zweifellos war nicht nur der Runenkundige, der auf der Pforzener Gürtelschnalle (Gü 1) die Anfangsverse eines germanischen Heldenepos einritzte, literarisch gebildet, sondern auch der Besitzer und Träger des Gürtels, falls dieser nicht mit jenem sogar identisch war.

\subsubsection{Religiöse Vorstellungen}

Für keines unserer Runengräber ist ein Münzobolus bezeugt. Dieser ursprünglich antike Grabbrauch wurde auch in der germanischen Welt rezipiert, zunächst - im späteren 4. Jahrhundert - bei den Franken, im Laufe des späteren

81 Vgl. etwa Zahlenverhältnisse von Männergräbern mit und ohne Spatha in Marktoberdorf (Allgäu) (Christlein 1966: 89-91). 
6. Jahrhunderts auch in der Alamannia. Wie überall im germanischen Milieu blieb er auf die Oberschicht beschränkt, wie auch aus der fast ausschließlichen Verwendung von Prägungen aus Edelmetall hervorgeht. Daß der Brauch nie zusammen mit Runen vorkommt, ist bemerkenswert. Dennoch wird man aus der Tatsache, daß die Sitte des Münzobolus auch im nordgermanischen Bereich unbekannt ist, noch keine weiterreichenden Schlüsse ziehen dürfen.

Auf einer der beiden Scheibenfibeln von Chéhéry (Dép. Ardennes) wurde oberhalb einer Runenzeile in lateinischen Buchstaben eine christliche Formel (DEOS : DE) eingeritzt (Abb. 8 (K 1)). Man erinnert sich dabei an die aus einem Kirchengrab im knapp $70 \mathrm{~km}$ weiter östlich gelegenen Arlon (Prov. Luxembourg) geborgene Runeninschrift, die an einer mit christlichem Kreuz geschmückten Amulettkapsel angebracht ist. ${ }^{82}$ Mit Chéhéry und Arlon befinden sich gleich zwei der drei am weitesten westlich entdeckten Runenritzungen die dritte repräsentiert das Futhark der Bügelfibel von Charnay (Abb. 6 (D 1)) - in eindeutig christlichem Kontext, ein klarer Kontrast zum Befund rechts des Rheins. Hier ist nur gerade eine Ausnahme anzuführen: Im Frauengrab 85 von Kirchheim u. Teck ist eine große, skandinavische Bügelfibel mit Runenritzung (Abb. 6 (D 5)) mit einem Goldblattkreuz vergesellschaftet, ein sicheres Zeichen dafür, daß die betreffende reiche Dame als Christin bestattet wurde. Im übrigen sind östlich des Rheins Gräber mit Runenfunden größtenteils älter als die dortigen frühesten Bestattungen in Kirchen. ${ }^{83}$

Angesichts der engen Einbindung der süddeutschen Runenritzungen in eine vielfältige, aus einzelnen Zuwanderungen, aber auch aus Importen und Einflüssen zusammengesetzte „Strömung“ aus dem vom Christentum noch gänzlich unberührten Norden (siehe unten) mutet es doch recht unwahrscheinlich an, daß einige Runenritzungen - genannt wurden vorab die der Bügelfibel von Nordendorf I (Abb. 6 (D 7)) und der Gürtelschnalle aus Pforzen Grab 239 (Gü 1), die beide noch im dritten Viertel des 6. Jahrhunderts in den Boden gelangt sein werden - in eine „,bekehrungsgeschichtliche Situation“ zu stellen seien. $^{84}$

Plausibler und in der Forschung seit langem akzeptiert ist ein christlicher Sinn bei der Runenzeile der Preßblechscheibenfibel von Osthofen (Abb. 7 (H 1)). Zum einen dürfte die Fibel - als eine der spätesten mit Runenritzung eine gute Generation später ins Grab mitgegeben worden sein als die beiden vorher genannten Objekte, zum andern gehört sie mit verwandten Stücken zu einer Gruppe auf mediterrane und zugleich christliche Motive zurückgreifender

\footnotetext{
82 Opitz Nr. 2; Nedoma 1992.

83 Vgl. Böhme 1996: Abb. 1-3.

84 Düwel 2001: 64. Die Pforzener Inschrift liest Nedoma überzeugend als Anfang eines verlorenen germanischen Epos (Nedoma 1999; sowie in diesem Band S. 340 ff.).
} 
Scheibenfibeln aus der Umgebung von Mainz ${ }^{85}$ dessen nach 451 verwaister Bischofssitz seit der Mitte des 6. Jahrhunderts wieder besetzt war. ${ }^{86}$

\subsubsection{Ort der Runenritzungen}

Sind außer dem jütlandischen Bügelfibelpaar von Donzdorf (Abb. 6 (D 4)) mit seinen vom Hersteller in Jütland angebrachten eho-Runen ${ }^{87}$ weitere Gegenstände bereits beschriftet nach Süden gelangt? In Frage kommen dafür nur im Süden fremde, d.h. nordische Objekte - und solche sind nicht zahlreich: Es sind die anderen beiden nordischen Bügelfibeln (Abb. 6 (D 3 und 5)) und das skandinavische Schwert mit Runenkreuz (Wa 2) sowie, aus archäologischer Sicht, möglicherweise auch noch - vielleicht nicht zufällig in Mitteldeutschland - die beidseits beschriftete Rahmenschnalle Gü 3 aus Weimar-Nordfriedhof Grab 56 und eine im gleichen Grab gefundene Bernsteinperle mit Runen, beide mit auffällig langen Runensequenzen. ${ }^{88}$ Alle übrigen Gegenstände, die Träger einer kontinentalen Runenritzung sind, wurden anscheinend, mit Ausnahme der Fibel von Charnay (Abb. 6 (D 1)), in dem Gebiet beschriftet, in dem sie heimisch waren und später auch ins Grab kamen. Für normalerweise geringe Distanzen zwischen Beschriftungsort und Deponierung im Grab scheint auch die räumliche Verteilung, d.h. die regionale Konzentration der Belege zu sprechen (Abb. 10 und 11). Größere geographische Verschiebungen der bereits beschrifteten Objekte oder ausgedehnte „Wanderungen“ ihrer Besitzer hätten vermutlich zu diffuseren Verbreitungsbildern geführt. ${ }^{89}$

\subsubsection{Ursachen und Verursacher der Runenritzungen}

Schwieriger als die Frage nach der Herkunft der runenritzenden Personen oder der Besitzer mit Runen versehener Gegenstände stellt sich - auch für den Archäologen - das Problem der kontinentalen Runeninschriften dar, wenn er nach den Gründen und Ursachen fragt, die den Anstoß gaben, Objekte der weibli-

85 Klein-Pfeuffer 1993: 134-137; U. Koch 2001: 260 und Abb. 110.

86 Zu weiteren Preßblechscheibenfibeln des 7. Jahrhunderts mit christlichen Motiven, die mit Mainzer Missionstätigkeit in Zusammenhang gebracht werden, vgl. Klein-Pfeuffer 1993: 50-54.

87 So zuletzt Düwel 2001: 60; die Donzdorfer Dame wird jedoch keine Alamannin gewesen sein, wie auch andere Beigaben bestätigen.

88 K.-J. Nr. 148 und 149; Opitz Nr. 51 und 52; Kat. Göttingen Nr. 55 (Rahmenschnalle).

89 Aus archäologischer Sicht ist beispielsweise gut denkbar, dass die Bülacher Granatscheibenfibel (Abb. 7 (E 6)), die vermutlich aus dem Mittelrheingebiet stammt, auch dort beschriftet wurde (Martin 1977: 126). 
chen Tracht, der männlichen Bewaffnung, des Gürtels usw. mit Runen zu beschriften. Unzweifelhaft kam dieser Brauch in Süddeutschland und angrenzenden Landschaften, insbesondere Mittelrhein und Mitteldeutschland, um die Mitte des. 6. Jahrhunderts neu und ohne jegliche einheimische Vorläufer auf und blieb nur wenige Jahrzehnte lebendig. Zu jener Zeit waren im Norden bereits seit gut drei Jahrhunderten in ähnlicher Art und Weise Gegenstände gleicher Funktion (d.h. Fibeln, Waffen usw.) mit Runen versehen worden.

War etwa den Franken und Alamannen oder den Westgermanen insgesamt während des 3. und 4. Jahrhunderts, als sie sich zunehmend nach Westen und Südwesten, zum Imperium Romanum hin orientierten, die möglicherweise erst seit dem 2. Jahrhundert nachweisbare Runenschrift ${ }^{90}$ gar nicht bekannt geworden oder ihnen fremd geblieben? Oder hatten sie, im Gegensatz zu Nord- und Ostgermanen, fast drei Jahrhunderte lang auf Runenritzungen verzichtet, um den Brauch schließlich, jedenfalls in einigen Landschaften, insbesondere der Alamannia, doch noch zu übernehmen - und nach wenigen Jahrzehnten wieder aufzugeben? Daß etwa die aus dem elbgermanischen Raum wegziehenden Vorfahren der späteren Alamannen die Runen nicht gekannt und mitgenommen hätten, scheint uns auch heute ebenso schwer verständlich wie seinerzeit $\mathrm{H}$. Arntz (vgl. 2.3.).

Entscheidendes Gewicht kommt der Tatsache zu, daß der aufkommende Brauch des Runenritzens nicht das einzige Element in den durch Runeninschriften sich auszeichnenden Regionen Süddeutschlands darstellt, das in den gleichen Jahrzehnten mit dem Norden und mit nordgermanischen Personen(gruppen) zusammengebracht werden kann. Seit dem mittleren 6. Jahrhundert findet sich in der Alamannia für einige Jahrzehnte manches, was auf Zuwanderungen und Einflüsse aus dem benachbarten Mitteldeutschland und dem nordgermanischen Raum allgemein hinweist: ${ }^{91}$ Ansiedlungen thüringischer Familien wie in Schretzheim, ${ }^{92}$ skandinavische Goldbrakteaten und Spathen sowie nicht zuletzt auch die neue, nordische Grundform der oben besprochenen Serien merowingischer Bügelfibeln.

Nordische Spathen sind nicht nur aus Schretzheim, wo auch eine Trense und somit vermutlich ein Pferd - nordischer Herkunft nachzuweisen ist, ${ }^{93}$ son-

90 Gegenüber der ins frühere 1. Jahrhundert datierten Fibel von Meldorf mit ihren fraglichen Runen liegen „die übrigen Runendenkmäler erst 100-150 Jahre später“ (Düwel 2001: 23 f.), was nicht gerade für eine Interpretation der Meldorfer Zeichen als Runen spricht.

91 Vgl. zum folgenden nebst früheren Angaben (Martin 1977 und 1997) unter anderem auch Wieczorek 1989 (mit mehrheitlich zu früher Datierung der von ihm bearbeiteten „handgemachten Keramik mitteldeutscher Formentradition“ [Listen 4-10]) und jetzt insbesondere U. Koch 1999. 
dern auch von anderen Orten Süddeutschlands bezeugt. Sie werden wie weitere nordische Objekte, z.B. Goldbrakteaten, mit ihren Besitzern, teilweise vielleicht auch als Import nach Süden gelangt sein. Die Mitgabe eiserner Webschwerter ins Grab hat damals als fremder, nordischer Brauch im Süden Eingang gefunden.

Am ehesten werden aus dem Norden zuziehende Bevölkerungsgruppen, zu denen die Dame aus Donzdorf (D 4) und der Spathaträger aus Schretzheim (Wa 2) sowie andere Personen gehörten, die wegen des herrschenden Kulturgefälles archäologisch nicht mehr faßbar sind, das Runenbrauchtum mitgebracht haben, das dann wahrscheinlich von einheimischen Personen für beschränkte Zeit übernommen wurde. Was das genannte Kulturgefälle angeht, so scheint „im Bereich des Kunsthandwerks auch der 'nordische Kreis' im 6. Jahrhundert gebender Teil “94 gewesen zu sein.

\section{Schluß}

$\mathrm{Zu}$ einem guten Teil häufen sich, wie bereits erwähnt, die fremden Objekte und fremdes Brauchtum in den gleichen Regionen wie unsere Runendenkmäler. Bezeichnend scheint mir, daß diese im Süden neuartigen, fremden „Erscheinungen“, von Personen mit nordischem Sachgut bis zu importierten Objekten und Einflüssen auf die Fibelmode, im großen ganzen dem gleichen Zeitraum angehören, dessen Beginn etwa kurz vor der Mitte des 6. Jahrhunderts anzusetzen ist.

Bereits Bernhard Salin hatte vor bald hundert Jahren erkannt, daß „die Kenntnis der Runen mit einer von Norden hervorbrechenden Strömung nach dem mittleren Europa gelangt ist. "95 Auslöser dieser "Strömung“, die nicht nur im Süden, sondern - in anderer Form - auch im Rheinland und westlich des Rheins spürbar ist, dürfte die Eroberung des Thüringerreiches durch die Franken (531) gewesen sein. ${ }^{96}$ Solange dieses bestand, bildete es einen Riegel oder Filter zwischen dem germanischen Norden und den seit langem der spätantiken, romanischen Welt zugewandten Franken, aber auch den Alamannen, spätestens nach deren Eingliederung ins fränkische Reich in den Jahren nach 500.

Nach dem Fall des thüringischen Königreiches, von dessen (politischen) Grenzen wir uns kaum ein Bild machen können, ${ }^{97}$ grenzte das stark expandierende ostfränkische Reich unter Theudebert I. (533-548) und seinen Nachfol-

94

95

96

97

Martin 1977: 126.

Salin 1935: 146. Gegen diese These wandte sich bekanntlich seinerzeit - zu Unrecht Zeiß, in: Arntz/Zeiß 1939: 213-215.

Vgl. dazu und zum folgenden bereits Martin 1977 und 1997.

Vgl. Weidemanns These eines mächtigen Thüringerreichs, das sich im Westen noch um 530 bis zum Niederrhein erstreckt habe (Weidemann 1976: 227-229 mit Karte). 
gern im Nordosten in weit größerem Ausmaß als bisher an die Gebiete der Sachsen und Nordgermanen. Die jetzt möglich gewordenen direkten Kontakte zwischen Nord und Süd dürften nicht ohne Auswirkungen auf das Merowingerreich geblieben sein:

Unter Chlodwig (482-511) und seinen Söhnen erfolgte im 6. Jahrhundert der fränkische Ausgriff östlich und nördlich der ehemals römischen Grenzen, der mit der Einverleibung des Thüringerreiches in den Jahren 529/531 seinen vorläufigen Abschluß fand. $^{98}$

Es ist sicher kein Zufall, wenn die einzigen beiden, übrigens lateinisch abgefaßten Schriftzeugnisse des Merowingerreiches, die von der germanischen Runenschrift berichten, in die Jahrzehnte um 560/80 - zeitlich der Höhepunkt der kontinentalen Runenzeugnisse - datieren: Zum einem hören wir, daß der fränkische König Chilperich (561-584) dem bestehenden Alphabet einige Buchstaben zufügte und dabei eine Form dem älteren Futhark entnahm, zum andern war es Venantius Fortunatus, der um 560/70 in einem Gedicht der Runenschrift gedachte. ${ }^{99}$

$\mathrm{Da}$ im Süden die Runenschrift ebenso rasch wieder verschwand wie sie gekommen war, ${ }^{100}$ ist ein letztes Argument gegen eine indigene, frühe Existenz dieser Schrift auf dem Kontinent, d.h. bei den sich im Laufe des 3./4. Jahrhunderts formierenden westgermanischen Stämmen der Franken, Alamannen, Thüringer und Langobarden. Der vor gut zehn Jahren formulierten These, es könnte die im Süden ,seit Alters vorhandene Runenkenntnis unter nordischem Einfluß eine Wiederbelebung seit dem 6. Jahrhundert" ${ }^{\text {"101 }}$ erfahren haben, wird man aus archäologischer Sicht nicht beipflichten können.

\section{Liste der mit Runen beschrifteten Fibeln, Waffen(teile) und Gürtelteile der Merowingerzeit}

\section{Literaturabkürzungen}

A.-J. = Arntz, Helmut/Jänichen, Hans. 1957.

A.-Z. = Arntz, Helmut/Zeiß, Hans. 1939.

Henning = Henning, Rudolf. 1889.

K.-J. = Krause, Wolfgang. 1966.

\footnotetext{
98 Müller-Wille 1999: 2.

99 Düwel 1994: $232 \mathrm{f}$.

100 Spätere, klösterliche Runenaufzeichnungen sind - wiederum - aus dem Norden ,importiert".

101 Düwel 1991: 283 .
} 
Kat. Göttingen $=$ Schmuck und Waffen mit Inschriften aus dem ersten Jahrtausend. Ausstellung Göttingen 1995. o. O. o. J. [1995].

Lindenschmit $=$ Lindenschmit, Ludwig. $1880-89$.

Opitz = Opitz, Stephan. 1977.

Werner $=$ Werner, Joachim. 1935.

A. Bügelfibeln mit gleichbreitem Fuß und halbrunder Kopfplatte (Abb. 4)

A 1a und b: aus Grab 303 von München-Aubing (Stadt München)

Opitz Nrn. 28, 29. - Kat. Göttingen Nr. 26. - K. Düwel, in: Dannheimer 1998: 75-78 und Abb. 13-15; Taf. 118 (1) und 119.

Mitfunde: Dannheimer 1998: 116 und Taf. 34 C.

A 2: aus Grab 115 von Basel-Kleinhüningen

Giesler-Müller 1992: 106 („,eingravierte, teilweise sich kreuzende Linien“ auf der Rückseite der Kopfplatte) und Taf. 23 (5) und 69 (5).

Mitfunde: Giesler-Müller 1992: Taf. 23 (1-4).

A 3: aus Grab 20 von Pleidelsheim (Kreis Ludwigsburg)

U. Koch 2001: 415 und Taf. 12 (2).

Mitfunde: U. Koch 2001: Taf. 12 B.

A 4: aus einem Grabfund von Hohenstadt (Kreis Göppingen)

Veeck 1931: 35, 319 und Taf. 22 A (1). - Schuchhardt 1936: Taf. 65 (265). Opitz Nr. 26 (mit photographischer Abb. der Rückseite). - Kat. Göttingen Nr. 17 (,Zweifel, ob es sich [...] um eine Runeninschrift handelt, [...] nicht ausgeräumt").

Mitfunde: unbekannt; vgl. Veeck 1931: 319.

B. Bügelfibeln mit ovaler (bzw. rautenförmiger) Fußplatte und halbrunder Kopfplatte (Abb. 5)

B 1: aus einem Grabfund von Freilaubersheim (Kreis Bad Kreuznach) Lindenschmit 490 und Fig. 459. - Henning Nr. VI. - A.-Z. Nr. 15. - K.-J. Nr. 144. - Opitz Nr. 16. - Kat. Göttingen Nr. 11.

Mitfunde: paarige Bügelfibel, Granatscheibenfibel, Perlen, Bergkristallwirtel, Glasbecher, Tongefäß usw. (A.-Z. 1939: 211). 
B 2a und b: aus Grab 57 von Weimar-Nordfriedhof A.-Z. Nr. 33 und 34. - K.-J. Nr. 147. - Opitz Nr. 49 und 50. - Kat. Göttingen Nr. 54.

Mitfunde: Schmidt 1970: 84 und Taf. 136 (1).

B 3: aus Grab 26 von Schretzheim (Stadt Dillingen a. d. Donau) U. Koch 1977: 164 und Taf. 11 (8 und 9), 191 (3 und 4) und 224 (2). Mitfunde: U. Koch 1977: Taf. 11.

B 4a und b: aus Grab 8 von Bezenye (Pallersdorf) (Kom. Mosony)

A.-Z. Nr. 27 und 28. - K.-J. Nr. 166. - Bóna 1956: Taf. 44 (1 und 2), 56 (4). Opitz Nr. 5 und 6.

Mitfunde: Bóna 1956: 192 und Taf. 44. - Werner 1962: Taf. 64.

B 5: aus einem Grabfund von Nordendorf II (Kreis Augsburg-Land)

Henning Nr. VIII. - A.-Z. Nr. 25. - K.-J. Nr. 152. - Opitz Nr. 34. - Kat. Göttingen Nr. 36. - Trier 2002: Taf. 116 (1) und 220 (4).

Mitfunde: unbekannt; vgl. Trier 2002: $426 \mathrm{f}$.

B 6: aus einem Grabfund von Bad Ems (Rhein-Lahn-Kreis)

Henning Nr. IX. - A.-Z. Nr. 12. - K.-J. Nr. 142. - Opitz Nr. 14. - Kat. Göttingen Nr. 10.

Mitfunde: unbekannt; vgl. Neumayer 1993: 161 und Taf. 1 (9) und 39 (2).

C. Bügelfibeln mit ovaler Fußplatte und rechteckiger Kopfplatte (Abb. 5)

C 1a und b: aus einem Grab von Dischingen (Kreis Heidenheim)

A.-J. 119ff. und Abb. 1 (1 und 2); Taf. 64 (1 und 2) und 65 (1 und 2). - K.-J. Nr. 155. - Opitz Nr. 11 und 12.

Mitfunde: Fundberichte aus Schwaben N. F. 13, 1952-1954, 91 und Taf. 17 (2).

C 2: aus Grab 43 von Griesheim (Kreis Darmstadt-Dieburg) Opitz Nr. 20. - Göldner/Hilberg 2000. - Düwel 2001: 60. Mitfunde: unpubliziert.

C 3: aus einem Grabfund von Herbrechtingen (Kreis Heidenheim) Werner Nr. 20. - A.-Z. Nr. 22. - K.-J. Nr. 154. - Opitz Nr.25. Mitfunde: Werner 1935: 87 und Taf. 9B-11A. 
C 4: aus einem Grabfund von Kaltenengers (Kreis Neuwied)

Henning Fig. 18 und 19 („Engers [bei Neuwied]“). - A.-Z. Nr. 13 („Kalten-Engers bei Koblenz"). K.-J. Nr. 143. - Opitz Nr. 15. - Haseloff 1981: 615 und Abb. 423; Taf. 81 (1).

Mitfunde: nur paarige Bügelfibel überliefert; Hanel 1994: 46 („Kaltenengers“, „Einzelfund“, ohne Hinweis auf die Runen) und Taf. 42 (6).

C 5a und b: aus Grab 11 von Trossingen (Kreis Tuttlingen)

A.-J. 122 f. und Taf. 64 (5 und 6) und 65 (3). - K.-J. Nr. 163. - Opitz Nr. 45 und 46. - Kat. Göttingen Nr. 49.

Mitfunde: Paret 1935-38: 144 und Taf. 35 (1).

D. Bügelfibeln mit „,barockem“ Fuß und rechteckiger Kopfplatte (Abb. 6)

D 1: aus Charnay (Dép. Saône-et-Loire)

Baudot 1857-60: 49-55 (mit Expertise von C. C. Rafn, Kopenhagen) und Taf. 14 (1). - Henning Nr. IV. - A.-Z. Nr. 11. - K.-J. Nr. 6. - Opitz Nr. 10. - RGA (2. Aufl.) Bd. 4 (Berlin/New York 1981) 372-375 s. v. Charnay (H. Roth; K. Düwel).

Mitfunde: unbekannt.

D 2: aus Grab 1 von Beuchte (Kreis Wolfenbüttel)

K.-J. Nr. 8. - Opitz Nr. 4. - Kat. Göttingen Nr. 4. - Düwel 2001: Abb. 7. Mitfunde: Niquet/Düwel 1976: 18-27.

D 3: aus Grab 166 von Aschheim (Kreis München-Land)

Düwel, in: Reimann u.a. 1999: 85 und Abb. 82.

Mitfunde: Reimann u.a. 1999: 83-85 und Abb. 81 (Grabplan).

D 4: aus Grab 78 von Donzdorf (Kreis Göppingen)

Opitz Nr. 13. - Kat. Göttingen Nr. 7. - Haseloff 1981: Abb. 24; Taf. 15-17. Düwel 2001: 60.

Mitfunde: Neuffer 1972: 86-88 und Taf. 22-24; 58-64; 65 (1); Farbtafel. - Haseloff 1981: Abb. 89 (1-3).

D 5: aus Grab 85 von Kirchheim u. Teck (Kreis Esslingen)

Opitz Nr. 27 (mit photographischer Abb. der Rückseite). - Haseloff 1981: Abb. 192; Taf. 39. - Kat. Göttingen Nr. 19002E

Mitfunde: Haseloff 1981: 288 f., 724 f. (E. Nau) und Taf. 94. - Vgl. auch Opitz Nr. 27. 
D 6: aus Grab 26 von Mertingen (Kreis Donau-Ries)

Babucke/Düwel 2000: 168-170 und Abb. 7-10.

Mitfunde: Babucke/Düwel 2000: 161-168 und Abb. 3-6.

D 7: aus einem Grabfund von Nordendorf I (Kreis Augsburg-Land)

Lindenschmit 489 f. und Fig. 458. - Henning Nr. VII. - A.-Z. Nr. 24. - K.-J. Nr. 151. - Opitz Nr. 33. - Kat. Göttingen Nr. 35. Trier 2002: Taf. 115 (11) und 221 (1).

Mitfunde: unbekannt; vgl. Trier 2002: 427.

D 8: aus Grab 319 von Neudingen (Schwarzwald-Baar-Kreis)

Kat. Göttingen Nr. 33. - Die Alamannen. Ausstellungskat. Stuttgart 1997: Abb. 581 (c). Brendle u.a. 2001: 349-374.

Mitfunde: Brendle u.a. 2001: Abb. 4 (3 und 4).

E. Granatscheibenfibeln (Abb. 7)

E 1: aus einem Grabfund von Gomadingen (Kreis Reutlingen)

Freundl. Mitt. D. Quast, Mainz.

Mitfunde: unpubliziert.

E 2: aus Grab 10 von Friedberg (Wetteraukreis) Henning Nr. X. - A.-Z. Nr. 16. - K.-J. Nr. 141. - Opitz Nr. 17. Mitfunde: unpubliziert (Opitz: „paarige Scheibenfibel, Krug, beinerner Kamm, Eisenschere, eisernes Messer, Spinnwirtel, eine Anzahl Perlen, Eisenschnalle, Doppelkamm, Tongefäß“").

E 3: aus Grab 509 von Schretzheim (Stadt Dillingen a. d. Donau) K.-J. Nr. 156. - U. Koch 1977: 164 und Taf. 193 (24 und 25) und 224 (1). Opitz Nr. 39.

Mitfunde: U. Koch 1977: Taf. 132 (4-15).

E 4: aus Grab 44 von Peigen, Markt Pilsting (Landkreis Dingolfing-Landau) Fischer 1988: Taf. 37 Mitte. - Düwel 1994: 277. - Düwel 2001: 67. Mitfunde: unpubliziert.

E 5: aus Grab 13 von Öttingen (Kreis Donau-Ries) Böhner 1979: Abb. 31. - Kat. Göttingen Nr. 38.

Mitfunde: Betz 1979: Abb. 1. - Böhner 1979: Abb. 30 (jeweils Grabplan und Rekonstruktion); laut Betz 1979: 242 Ohrring, S-Fibel, Perlen, Bronzeschnalle, Amulette, Kamm usw.). 
E 6: aus Grab 249 von Bülach (Kanton Zürich)

A.-Z. Nr. 10. - Werner 1953: 10, 123 und Abb. 2; Taf. 1 (10). - K.-J. Nr. 165. - Opitz Nr. 9.

Mitfunde: Werner 1953: 123 mit Abb.

E 7: aus Grab 106 von Soest (Westfalen)

Werner Nr. 30. - A.-Z. Nr. 30. - K.-J. Nr. 140. - Opitz Nr. 41. - Kat. Göttingen Nr. 44.

Mitfunde: Werner 1935: 92 f. und Taf. 17 und 18.

F. Filigranscheibenfibel (Abb. 7)

F 1: aus Balingen (Zollernalbkreis)

A.-Z. Nr. 7. - K.-J. Nr. 160. - Opitz Nr. 3. - Kat. Göttingen Nr. 3.

Mitfunde: unbekannt.

F 2: aus Grab 86 von Weißenburg (Kreis Weißenburg-Gunzenhausen)

Opitz Nr. 55. - Düwel 1994: 277 („nicht sicher runische Inschrift“). - Jemiller 1995/1996: 190 f., 254 und Abb. 4; Taf. 28 (13) (ohne Erwähnung der Runen). Mitfunde: Jemiller 1995/96: 254 und Taf. 28 (14).

G. Vierpaßfibel aus vergoldeter Bronze (?)

G 1: aus Grabfund von Bopfingen (Kreis Heidenheim)

Opitz Nr. 7 („Vierpaßfibel“, mit photographischer Abb. der Rückseite).

Mitfunde: unpubliziert (Opitz: „2 Bügelfibeln, Beinwirtel, Bronzeschnalle, Beinkamm, Eisenmesser, Perlen").

H. Preßblechscheibenfibel (Abb. 7)

H 1: aus Osthofen (Kreis Alzey-Worms)

Lindenschmit Fig. 460; Taf. 21 (9). - Henning Nr. V. - A.-Z. Nr. 26. - K.-J. Nr. 145. - Opitz Nr. 36. - Klein-Pfeuffer 1993: 134 ff., 430 ff. und Abb. 39 (1); Taf. 55 (258). - Kat. Göttingen Nr. 39. - U. Koch 2001: 260 und Abb. 110 .

Mitfunde: unbekannt. 
I. S-Fibeln (Abb. 8)

I 1: aus Grab 33 von Szentendre (Kom. Pest)

Bóna 1970-71: Abb. 10 (2 und 4). - Martin 1997: 502, Anm. 3.

Mitfunde: Bóna 1970-71: Abb. 9-11.

I 2: aus Grab 179 von Weingarten (Kreis Ravensburg)

A.-J. 128 und Abb. 1 (5); Taf. 64 (4) und 65 (6). - K.-J. Nr. 164. - Opitz Nr. 54 .

Mitfunde: Roth/Theune 1995: 54 und Taf. 55 C.

I 3: aus Grab 406 von Hailfingen (Kreis Tübingen)

Fundbericht Schwaben N. F. 16, 1962, 156 f. und Taf. N. - Opitz Nr. 22 (mit photographischer Abb. der Rückseite).

Mitfunde: Stoll 1939: 66 und Taf. 17 (4), 20 (19), 21 (28) und 25 (23).

I 4: aus Grab 272 von Weingarten (Kreis Ravensburg)

A.-J. 126 ff. und Abb. 1 (4); Taf. 64 (7) und 65 (5). - K.-J. Nr. 164. - Opitz Nr. 53.

Mitfunde: Roth/Theune 1995: 79 f. und Taf. 96 A.

I 5: aus Grab 33 von Schwangau (Kreis Ostallgäu)

Christlein 1978: 113 und Abb. 88. - Bachran 1993: 27 und Taf. 15 (3). Düwel 1994: 277. - Kat. Göttingen Nr. 41.

Mitfunde: Bachran 1993: 27-31 (Preßblechscheibenfibel, Perlen, zwei konische Beinamulette, 14 römische Münzen, Gürtelschnalle, Messer, Kamm, Wadenbindengarnitur).

K. Scheibenfibeln mit Tierkopfwirbel (Abb. 8)

K 1: aus einem Grabfund von Chéhéry (dép. Ardennes)

Kat. Göttingen Nr. 5. - Fischer 2000: Fig. 1.

Mitfunde: teilweise publiziert; vgl. Fischer 2000.

K 2: aus Grab 163 von München-Aubing (Stadt München)

Opitz Nr. 30. - Kat. Göttingen Nr. 27. - Düwel, in: Dannheimer 1998: 78 und Abb. 16; Taf. 118 (2).

Mitfunde: Dannheimer 1998: 101 und Taf. 18 B und 99 (10). 
K 3: aus Grab 383 von München-Aubing (Stadt München)

Opitz Nr. 31. - Kat. Göttingen Nr. 28. - Düwel, in: Dannheimer 1998: 78 f. und Abb. 17; Taf. 118 (3).

Mitfunde: Dannheimer 1998: 127 und Taf. 43 A und 99 (9).

Wa. Mit Runen versehene Waffen der Merowingerzeit (Abb. 9,1)

Wa 1: Lanzenspitze aus Grab 2 von Wurmlingen (Kreis Tuttlingen)

A.-Z. Nr. 40. - K.-J. Nr. 162. - Opitz Nr. 56. - Düwel 2001: 62.

Mitfunde: unpubliziert (Spathagurt[?]teile, Sax, Messer, Gürtelgarnitur).

Wa 2: Spatha aus Grab 79 von Schretzheim (Landkreis Dillingen a. d. Donau) Klingenberg/Koch 1974: 120-130 und Taf. 32. - Koch 1977: 164 f. und Taf. 183 (9); 210 (2). - Opitz Nr. 40. - Koch 1999: 185-187.

Mitfunde: Koch 1977: Taf. 25 (1-4).

Wa 3: Mundblech einer Spathascheide aus Grab 186 von Eichstetten (Kreis Breisgau-Hochschwarzwald)

Opitz 1982; Abb. 1-3. - Kat. Göttingen Nr. 9. - Sasse 2001: 80 f. und Abb. 17; Taf. 79 (3).

Mitfunde: Sasse 2001: 206 f. und Taf. 78 B; 79.

Wa 4: Mundblech einer Spathascheide aus Grab 1 von Bopfingen (Kreis Heidenheim)

Arntz/Böhner 1954. - Düwel 1994: 235 („Lateinbuchstaben oder Runenzeichen“) und 268. - Düwel 2001: 67 („Pseudorunen“).

Mitfunde: Arntz/Böhner 1954: Abb. 1 und 2.

Wa 5: Schmalsax (Klingenlänge $30 \mathrm{~cm}$ ) aus Grab 40 von Gräfelfing (Stadt München)

Opitz Nr. 19. - Kat. Göttingen Nr. 14.

Mitfunde: Spatha, Spathagurtteile, punzverzierte Gürtelgarnitur aus Bronze (Schnalle, Rückenplatte und zwei Ösenbeschläge mit Tierkopf), Messer, Schere (Archäologische Staatssammlung München, Inv. 1936, 94-107).

Wa 6: Schmalsax (Klingenlänge $29 \mathrm{~cm}$ ) aus Grab 381 von Hailfingen (Kreis Tübingen)

A.-Z. Nr. 18. - K.-J. Nr. 159. - Opitz Nr. 21. - Kat. Göttingen Nr. 15 (,runenähnliche Dekoration“?). - Düwel 2001: 67 („Pseudorunen“).

Mitfunde: Stoll 1939: 64 und Taf. 22 (16) und 35 (13). 
Wa 7: Kurzsax (Klingenlänge $24 \mathrm{~cm}$ ) aus Grab 10 von Steindorf (Kreis Fürstenfeldbruck)

A.-Z. Nr. 31 (fälschlicherweise „Grab 8“). - K.-J. Nr. 158. - Opitz Nr. 42 („Grab 8“). - Düwel 2001: 62.

Mitfunde: keine.

Gü. Mit Runen versehene Gürtelteile der Merowingerzeit (Abb. 9,2)

Gü 1: Gürtelschnalle aus Grab 239 von Pforzen (Kreis Ostallgäu)

Kat. Göttingen Nr. 40. - Düwel, in: Babucke. 1999. Abb. 1; Taf. 1-4. - Nedoma 1999.

Mitfunde: Babucke 1999a: Abb. 2 und 3.

Gü 2: Gürtelbeschlag aus Grab 42 von Heilbronn-Böckingen

A.-J. 124 f. und Abb. 1 (3); Taf. 64 (11). - K.-J. Nr. 153. - Opitz Nr. 23. - U. Koch 1994: 40 f. und Abb. 43 und 44.

Mitfunde: Fundbericht Schwaben N. F. 14 (1957), 211 und Taf. 31 C. - U. Koch 1994: Abb. 44.

Gü 3: Rahmenschnalle aus Grab 56 von Weimar-Nordfriedhof A.-Z. Nr. 35. - K.-J. Nr. 148. - Opitz Nr. 51. - Kat. Göttingen Nr. 55. Mitfunde: Schmidt 1970: 84 und Taf. 90 (1).

Gü 4: Riemenzunge aus Grab 3a von Niederstotzingen (Kreis Heidenheim) Opitz Nr. 32. - Kat. Göttingen Nr. 34. - Düwel 2001: 67 („echte Runen und runenähnliche Zeichen oder Pseudorunen").

Mitfunde: Paulsen 1966: Taf. 77 und 86.

Gü 5a und b: Paar Riemenzungen aus Grab 22 von Trossingen (Kr. Tuttlingen) A.-J. 123 f. und Taf. 64 (9 und 10) und 65 (4). - K.-J. Nr. 163. - Opitz Nr. 47 und 48. - Kat. Göttingen Nr. 50.

Mitfunde: Paret 1935-38: 145 und Taf. 34 (1); 35 (3). - Kühn 1974: 414 und Taf. 210 (zu Nr. 362). 


\section{Literatur}

Ament, Hermann. 1992. Das alamannische Gräberfeld von Eschborn. (Materialien zur Vor- und Frühgeschichte von Hessen 14). Wiesbaden.

Arntz, Helmut/Böhner, Kurt. 1956. Ein Spathascheidenmundblech mit runischen(?) Zeichen im Museum Nördlingen. In: Bayerische Vorgeschichtsblätter 20, 145-149.

Arntz, Helmut/Jänichen, Hans. 1957. Neue Runeninschriften aus Württemberg. In: Fundberichte aus Schwaben N. F. 14, 117-131.

Arntz, Helmut/Zeiß, Hans. 1939. Die einheimischen Runendenkmäler des Festlandes. Gesamtausgabe der älteren Runendenkmäler I. Leipzig.

Babucke, Volker. 1999a. Die Runenschnalle von Pforzen (Allgäu). Aspekte der Deutung. 1. Zur Herkunft und Datierung. Archäologischer Befund. In: Bammesberger, Alfred (Hrsg.). 1999, 15-24.

Babucke, Volker. 1999b. Die Runeninschrift auf dem Elfenbeinring von Pforzen (Allgäu). In: Bammesberger, Alfred (Hrsg.). 1999, 121-126.

Babucke, Volker/Düwel, Klaus. 2000. Eine Bügelfibel mit Runeninschrift aus dem frühmittelalterlichen Gräberfeld von Mertingen. (Augsburger Beiträge zur Archäologie 3). Augsburg, 161-170.

Bachran, Walter. 1993. Das alamannische Reihengräberfeld von Schwangau, Landkreis Ostallgäu. Diss. Mainz.

Bammesberger, Alfred (Hrsg.). 1999. Pforzen und Bergakker. Neue Untersuchungen zu Runeninschriften. Göttingen.

Baudot, Henri. 1857-60. Mémoire sur les sépultures des barbares de l'époque mérovingienne découvertes en Bourgogne et particulièrement à Charnay. In: Mémoires Comm. des antiquités du dép. de la Côte-d'Or 5.

Betz, Werner. 1979. Dän. AUJA 'Glück' bei den Alemannen um 575? In: Archiv für das Studium der neueren Sprachen und Literatur 216, 241-245.

Bierbrauer, Volker. 1993. Die Landnahme der Langobarden in Italien aus archäologischer Sicht. In: Müller-Wille, Michael/Schneider, Reinhard (Hrsg.). Ausgewählte Probleme europäischer Landnahmen des Früh- und Hochmittelalters. (Vorträge und Forschungen 41/1). Sigmaringen, 103-172.

Bierbrauer, Volker. 1994. Archäologie und Geschichte der Goten vom 1.-7. Jahrhundert. In: Frühmittelalterliche Studien 28, 51-171.

Böhme, Horst Wolfgang. 1974. Germanische Grabfunde des 4. bis 5. Jahrhunderts zwischen unterer Elbe und Loire. (Münchner Beiträge zur Vor- und Frühgeschichte 19). München.

Böhme, Horst Wolfgang. 1985. Les découvertes du Bas-Empire à Vireux-Molhain. Considérations générales. In: Lemant, Jean-Pierre. 1985, 76-88.

Böhme, Horst Wolfgang. 1996. Adel und Kirche bei den Alamannen der Merowingerzeit. In: Germania 74, 477-507.

Böhme, Horst Wolfgang. 1999. Franken oder Sachsen? Beiträge zur Siedlungs- und Bevölkerungsgeschichte in Westfalen vom 4.-7. Jahrhundert. In: Studien zur Sachsenforschung 12, 43-73. 
Böhner, Kurt. 1979. Alamannische Reihengräberfriedhöfe im Ries. In: Frei, Hans/Krahe, Günther. Archäologische Wanderungen im Ries. Führer zu archäologischen Denkmälern in Bayern. Schwaben 2. Stuttgart/Aalen, 88-102.

Bóna, Istvan. 1956. Die Langobarden in Ungarn. In: Acta Archaeologica Academiae scientiarum Hungaricae 7, 183-244.

Bóna, Istvan. 1970-71. Langobarden in Ungarn. In: Arheoloski Vestnik 21/22, 45-74.

Brendle, Tobias u.a. 2001. Eine Bügelfibel aus Grab 319 des Gräberfeldes von Neudingen, Stadt Donaueschingen, Schwarzwald-Baar-Kreis. In: Pohl, Ernst u.a. (Hrsg.). Archäologisches Zellwerk. Beiträge zur Kulturgeschichte in Europa und Asien. Festschrift für Helmut Roth zum 60. Geburtstag. (Internationale Archäologie. Studia honoraria 16). Rahden, 345-374.

Christlein, Rainer. 1966. Das alamannische Reihengräberfeld von Marktoberdorf im Allgäu. (Materialhefte zur Bayerischen Vorgeschichte 21). Kallmünz/Opf.

Christlein, Rainer. 1978. Die Alamannen. Stuttgart.

Cosack, Erhard. 1982. Das sächsische Gräberfeld bei Liebenau, Kr. Niemburg (Weser). Teil 1. (Germanische Denkmäler der Völkerwanderungszeit Serie A, 15). Berlin.

Dannheimer, Hermann. 1962. Die germanischen Funde der späten Kaiserzeit und des frühen Mittelalters in Mittelfranken. (Germanische Denkmäler der Völkerwanderungszeit Serie A, 7). Berlin.

Dannheimer, Hermann. 1998. Das baiuwarische Reihengräberfeld von Aubing, Stadt München. (Monographien Prähistorische Staatssammlung München 1). Stuttgart.

Die Alamannen. 1997. Ausstellungskatalog. Hrsg. v. Archäologischen Landesmuseum Baden-Württemberg. Stuttgart.

Düwel, Klaus. 1991. Kontinentale Runeninschriften. In: Bammesberger, Alfred (Hrsg.). Old English Runes and their Continental Background. Heidelberg, 271-286.

Düwel, Klaus. 1994. Runische und lateinische Epigraphik im süddeutschen Raum zur Merowingerzeit. In: Düwel, Klaus (Hrsg.). 1994, 229-308.

Düwel, Klaus (Hrsg.). 1994. Runische Schriftkultur in kontinental-skandinavischer und -angelsächsischer Wechselbeziehung. (RGA-E 10). Berlin/New York.

Düwel, Klaus. 2001. Runenkunde. 3. Aufl. (Slg. Metzler 72). Stuttgart/Weimar.

Fischer, Svante. 2000. Runes, Latin and Christianity in Merovingian Gaul. Uppsala.

Fischer, Thomas. 1988. Römer und Bajuwaren an der Donau. Bilder zur Frühgeschichte Ostbayerns. Regensburg.

Freeden, Uta von. 2000. Das Ende engzelligen Cloisonnés und die Eroberung Südarabiens durch die Sasaniden. In: Germania 78, 97-124.

Freeden, Uta von/Koch, Ursula/Wieczorek, Alfried. (Hrsg.). 1999. Völker an Nordund Ostsee und die Franken. Akten des 48. Sachsensymposiums Mannheim 1997. Römisch-Germanische Kommission Frankfurt a.M., Eurasien-Abteilung. (Kolloquien zur Vor- und Frühgeschichte 3). Berlin.

Geisler, Hans. 1998. Das frühbairische Gräberfeld Straubing-Bajuwarenstrasse I. (Internationale Archäologie 30). Rahden/Westfalen. 
Germanen, Hunnen und Awaren. Schätze der Völkerwanderungszeit. 1987. Ausstellungskatalog. Hrsg. v. Wilfried Menghin/Tobias Springer/Egon Wamers. Nürnberg.

Giesler-Müller, Ulrike. 1992. Das frühmittelalterliche Gräberfeld von Basel-Kleinhüningen. Katalog und Tafeln. (Basler Beiträge zur Ur- und Frühgeschichte 11 B). Derendingen/Solothurn.

Göldner, Holger/Hilberg, Volker. 2001. Griesheim, Kreis-Darmstadt-Dieburg. Gräberfelder des 6. bis 8. Jahrhunderts. 2. Aufl. (Archäologische Denkmäler in Hessen 1). Wiesbaden.

Hanel, Eva. 1994. Die merowingischen Altertümer von Kärlich und Umgebung (Verbandsgem. Weißenthurm, Kr. Mayen-Koblenz). (Archäologische Schriften des Instituts für Vor- und Frühgeschichte der Johannes-Gutenberg-Universität Mainz 4). Mainz.

Haseloff, Günther. 1981. Die germanische Tierornamentik der Völkerwanderungszeit. Studien zu Salin's Stil I. (Vorgeschichtliche Forschungen 17). Berlin/New York.

Henning, Rudolf. 1889. Die deutschen Runendenkmäler. Straßburg.

Jänichen, Hans. 1967. Neue Inschriften aus alamannischen Gräbern des 7. Jahrhunderts. In: Fundberichte aus Schwaben N. F. 18/I, 232-238.

Jemiller, Elfi. 1995/96. Gräber der jüngeren Merowingerzeit aus Weißenburg in Bayern. In: Bericht der Bayerischen Bodendenkmalpflege 36/37, 169-306.

Kiss, Attila. 1980. Germanische Funde aus Szabadbattyán aus dem 5. Jahrhundert. In: Alba Regia 18, 105-132.

Kiss, Attila. 2001. Das germanische Frauengrab von Répcelak (Westungarn) aus der zweiten Hälfte des 5. Jahrhunderts. In: Acta Archaeologica Academiae Scientiarum Hungaricae 52, 115-144.

Klein-Pfeuffer, Margarete. 1993. Merowingerzeitliche Fibeln und Anhänger aus Preßblech. (Marburger Studien zur Vor- und Frühgeschichte 14). Marburg.

Klingenberg, Heinz/Koch, Ursula. 1974. Ein Ringschwert mit Runenkreuz aus Schretzheim, Kr. Dillingen a. d. Donau. In: Germania 52, 120-130.

Koch, Alexander. 1998. Bügelfibeln der Merowingerzeit im westlichen Frankenreich. (Monographien des Römisch-Germanischen Zentralmuseums Mainz 41). Mainz.

Koch, Robert. 1967. Bodenfunde der Völkerwanderungszeit aus dem Main-Tauber-Gebiet. (Germanische Denkmäler der Völkerwanderungszeit Serie A, 8). Berlin.

Koch, Ursula. 1977. Das Reihengräberfeld bei Schretzheim. (Germanische Denkmäler der Völkerwanderungszeit. Serie A, 13). Berlin.

Koch, Ursula. 1994. Franken in Heilbronn. In: Veröffentlichungen der Städtischen Museen Heilbronn, museo 8.

Koch, Ursula. 1999. Nordeuropäisches Fundmaterial in Gräbern Süddeutschlands rechts des Rheins. In: Freeden, Uta von/Koch, Ursula/Wieczorek, Alfried (Hrsg.). 1999, 175-194.

Koch, Ursula. 2001. Das alamannisch-fränkische Gräberfeld bei Pleidelsheim. (Forschungen und Berichte zur Vor- und Frühgeschichte in Baden-Württemberg 60). Stuttgart. 
Krause, Wolfgang. 1966. (= K.-J.). Die Runeninschriften im älteren Futhark. Mit Beiträgen von H. Jankuhn. (Abhandlungen Akademie Wissenschaften Göttingen Phil.Hist. Kl. 3. Folge, Nr. 65). Göttingen.

Krause, Wolfgang/Niquet, Franz. 1956. Die Runenfibel von Beuchte, Kreis Goslar. (Nachrichten Akademie der Wissenschaften Göttingen. I. Phil.-Hist. Kl. Nr. 5). Göttingen.

Kühn, Herbert. 1974. Die germanischen Bügelfibeln der Völkerwanderungszeit in Süddeutschland. Graz.

Lemant, Jean-Pierre. 1985. Le cimetière et la fortification du Bas-Empire de VireuxMolhain, dép. Ardennes. (Monographien RGZM 7). Mainz.

Lindenschmit, Ludwig. 1880-89. Handbuch der deutschen Alterthumskunde. 1. Teil. Die Alterthümer der merowingischen Zeit. Braunschweig.

Martin, Max. 1977. Die Runenfibel aus Bülach Grab 249. Gedanken zur Verbreitung der Runendenkmäler bei den Westgermanen. In: Stüber, Karl/Zürcher, Andreas (Hrsg.). Festschrift f. Walter Drack. Stäfa, 120-128.

Martin, Max. 1991. Das spätrömisch-frühmittelalterliche Gräberfeld von Kaiseraugst, Kt. Aargau. (Basler Beiträge zur Ur- und Frühgeschichte 5 A). Derendingen.

Martin, Max. (1991) 1995. Tradition und Wandel der fibelgeschmückten frühmittelalterlichen Frauenkleidung. In: Jahrbuch RGZM 38, 629-680.

Martin, Max. 1997. Schrift aus dem Norden. In: Die Alamannen. Ausstellungskatalog. Stuttgart, 499-502.

Müller, Hermann Friedrich. 1976. Das alamannische Gräberfeld von Hemmingen (Kreis Ludwigsburg). (Forschungen und Berichte zur Vor- und Frühgeschichte in Baden-Württemberg 7). Stuttgart.

Müller-Wille, Michael. 1999. Das Frankenreich und der Norden. Zur Archäologie wechselseitiger Beziehungen während der Merowinger- und frühen Karolingerzeit. In: Freeden, Uta von/Koch, Ursula/Wieczorek, Alfried (Hrsg.). 1999, 1-18.

Nagy, Margit. 1993. Óbuda a népvándorlás korban. In: Budapest Régiségei 30, 353395.

Nedoma, Robert. 1992. Votrilo und die Runeninschrift auf der Kapsel von Arlon. In: Amsterdamer Beiträge zur Älteren Germanistik 35, 1-6.

Nedoma, Robert. 1999. Die Runeninschrift auf der Gürtelschnalle von Pforzen - ein Zeugnis der germanischen Heldensage. In: Bammesberger, Alfred (Hrsg.). 1999, 98-109.

Nedoma, Robert. 2000. Runologische Deutung der Inschrift. In: Wamers, Egon. 2000, 24-28.

Neuffer, Eduard M. 1972. Der Reihengräberfriedhof von Donzdorf (Kreis Göppingen). (Forschungen und Berichte zur Vor- u. Frühgeschichte in Baden-Württemberg 2). Stuttgart.

Neumayer, Heino. 1993. Die merowingerzeitlichen Grabfunde des Mittelrheingebietes zwischen Nahe- und Moselmündung. (Archäologische Schriften des Instituts für Vor- und Frühgeschichte der Johannes-Gutenberg-Universität Mainz 2). Mainz. 
Niquet, Franz/Düwel, Klaus. 1976. Beuchte, Kreis Wolfenbüttel. In: Busch, Ralf (Hrsg.). Frühgeschichtliche Funde aus dem Braunschweiger Land. (Veröffentlichungen des Braunschweiger Landesmuseums 6). Göttingen, 18-23.

Oeftiger, Claus/Dollhopf, Klaus-Dieter. 2001. Fortsetzung der Ausgrabungen im alamannischen Gräberfeld „Zwerchweg“ bei Herrenberg, Kreis Böblingen. In: Archäologische Ausgrabungen in Baden-Württemberg 2000, 140-145.

Opitz, Stephan. 1977. Südgermanische Runeninschriften im älteren Futhark aus der Merowingerzeit. Kirchzarten.

Opitz, Stephan. 1982. Neue Runeninschriften. In: Fundberichte aus Baden-Württemberg 7, 481-490.

Paret, Oscar. 1935-38. Das Gräberfeld von Trossingen. In: Fundberichte aus Schwaben N. F. 9, 141-145.

Paulsen, Peter. 1967. Alamannische Adelsgräber von Niederstotzingen (Kreis Heidenheim). (Veröffentlichungen des Staatlichen Amtes für Denkmalpflege Stuttgart. Reihe A: Vor- und Frühgeschichte 12). Stuttgart.

Pirling, Renate. 1979. Das römisch-fränkische Gräberfeld von Krefeld-Gellep 1964 1965. (Germanische Denkmäler der Völkerwanderungszeit, Serie B, 10). Berlin.

Quak, Arend. 1994. Die friesischen Inschriften im Spiegel Kontinental-Angelsächsischer Wechselbeziehung. In: Düwel, Klaus (Hrsg.). 1994, 221-228.

Reimann, Dorit. 1997. Mode aus Byzanz - Frauengrab 10 aus Aschheim. In: Das Archäologische Jahr in Bayern 1997, 137-139.

Reimann, Dorit u.a. 1999. Vereint in den Tod - Doppelgrab 166/167 aus Aschheim. In: Das Archäologische Jahr in Bayern 1999, 83-85.

Roth, Helmut/Theune, Claudia. 1995. Das frühmittelalterliche Gräberfeld von Weingarten I. (Forschungen und Berichte zur Vor- und Frühgeschichte in Baden-Württemberg 44/I). Stuttgart.

Roth, Helmut/Wamers, Egon (Hrsg.). 1984. Hessen im Frühmittelalter. Sigmaringen.

Salin, Bernhard. 1935. Die altgermanische Thierornamentik. 2. Aufl. Stockholm.

Sasse, Barbara. 2001. Ein frühmittelalterliches Reihengräberfeld bei Eichstetten am Kaiserstuhl. (Forschungen und Berichte zur Vor- u. Frühgeschichte in BadenWürttemberg 75). Stuttgart.

Schön, Matthias D. 1999. Feddersen Wierde, Fallward, Flögeln. Bremerhaven.

Schmidt, Berthold. 1970. Die späte Völkerwanderungszeit in Mitteldeutschland. Kata$\log$ (Südteil). (Veröffentlichungen des Landesmuseums für Vorgeschichte in Halle 25). Berlin.

Schuchhardt, Carl. 1936. Deutsche Vor- und Frühgeschichte in Bildern. München/Berlin.

Seebold, Elmar. 1994. Die sprachliche Deutung und Einordnung der archaischen Runeninschriften. In: Düwel, Klaus (Hrsg.). 1994, 56-94.

Severin zwischen Römerzeit und Völkerwanderung. Ausstellungskatalog Stadtmuseum Enns 1982. Hrsg. v. Land Oberösterreich. Linz.

Steeger, Albert. 1937. Germanische Funde der Völkerwanderungszeit aus Krefeld. Krefeld. 
Stein, Frauke. 1987. Zur archäologischen Datierung einiger kontinentaler Runendenkmäler. Anhang zu: Haubrichs, Wolfgang. Lautverschiebung in Lothringen. Zur althochdeutschen Integration vorgermanischer Toponyme der historischen Sprachlandschaft zwischen Saar und Mosel. In: Bergmann, Rolf u.a. (Hrsg.). Althochdeutsch. Band II: Wörter und Namen. Forschungsgeschichte. Heidelberg, 13921400 .

Stoll, Hermann. 1939. Die Alamannengräber von Hailfingen in Württemberg. (Germanische Denkmäler der Völkerwanderungszeit 4). Berlin.

Tejral, Jaroslav. 1973. Mähren im 5. Jahrhundert. (Studie arch. ustavu ceskoslovenske akad ved v Brne I/1972). Praha.

Thieme, Bettina. 1978. Filigranscheibenfibeln der Merowingerzeit aus Deutschland. In: Bericht Römisch-Germanische Kommission 59, 381-500.

Trier, Marcus. 2002. Die frühmittelalterliche Besiedelung des unteren und mittleren Lechtals nach archäologischen Quellen. (Materialhefte zur Bayerischen Vorgeschichte, Reihe A, 84). Kallmünz.

Veeck, Walter. 1931. Die Alamannen in Württemberg. (Germanische Denkmäler der Völkerwanderungszeit 1). Berlin/Leipzig.

Vielitz, Kathrin. 2003. Die Granatscheibenfibeln der Merowingerzeit. (Europe médiévale 3). Montagnac.

Wamers, Egon. 2000. Der Runenreif aus Aalen. (Archäologische Reihe 17). Frankfurt am Main.

Weidemann, Konrad. 1976. Das Land zwischen Elbe- und Wesermündung vom 6.-8. Jahrhundert. In: Das Elb-Weserdreieck I. Führer zu vor- und frühgeschichtlichen Denkmälern 29, 227-250.

Werner, Joachim. 1935. Münzdatierte austrasische Grabfunde. (Germanische Denkmäler der Völkerwanderungszeit 3). Berlin/Leipzig.

Werner, Joachim. 1953. Das alamannische Gräberfeld von Bülach. (Monographien zur Ur- und Frühgeschichte der Schweiz 9). Basel.

Werner, Joachim. 1962. Die Langobarden in Pannonien. (Bayerische Akademie Wissenschaften. Phil.-hist. Klasse Abhandlungen N. F. 55). München.

Werner, Joachim. 1966. Das Aufkommen von Bild und Schrift in Nordeuropa. (Sitzungsberichte Bayerische Akademie Wissenschaften München, Phil.-Hist. Kl. 4). München.

Werner, Joachim. 1988. Danceny und Brangstrup. In: Bonner Jahrbücher 188, 241286.

Wieczorek, Alfried. 1989. Mitteldeutsche Siedler bei der fränkischen Landnahme in Rheinhessen. In: Das Dorf am Mittelrhein. Fünftes Alzeyer Kolloquium. Stuttgart, 11-101.

Windler, Renata. 1989. Ein frühmittelalterliches Männergrab aus Elgg (ZH). Bemerkungen zu einem filigranverzierten Schnallentyp. In: Jahrbuch Schweizerische Gesellschaft für Ur- und Frühgeschichte 72, 181-200.

Zeller, Gudula. 1994. Neue fränkische Funde aus Dalsheim, Kr. Alzey-Worms. In: Mainzer Archäologische Zeitschrift 1, 157-164. 